\begin{tabular}{cc}
$\begin{array}{c}\text { Teoria de la Educación } \\
\text { Educación y Cultura en la } \\
\text { VNiVERSIDAD } \\
\text { BSALAMANCA }\end{array}$ & Sociedad de la Información \\
\hline TESI,11 (3), 2010,32-68 &
\end{tabular}

\title{
EL IMPACTO DE LAS TIC EN LA TRANSFORMACIÓN DE LA ENSEÑANZA UNIVERSITARIA: REPENSAR LOS MODELOS DE ENSEÑANZA Y APRENDIZAJE
}

\section{Resumen:}

En los últimos años el debate sobre el uso de las TIC en las universidades se ha convertido en un tema estrella. En la educación superior las TIC, a menudo, se perciben como un catalizador para el cambio, en el estilo de enseñanza, en los métodos de aprendizaje y en el acceso a la información. Existen expectativas de que su utilización beneficie el ambiente de aprendizaje de los estudiantes.

Con este artículo intentaremos dar a conocer, y conscientes de nuestra gran osadía, algunos debates y planteamientos que surgen de la investigación en relación a las TIC y la educación superior. Acepto de antemano las críticas a mi atrevida pretensión. No pretendemos ser originales y admitimos que tenemos más preguntas que respuestas al examinar qué está pasando realmente con el uso de las TIC en la educación universitaria.

El artículo sugiere que no se trata de las tecnologías sino de los propósitos educativos y de la pedagogía que deben proporcionar el liderazgo en la comprensión no sólo de cómo trabajar con las TIC sino de por qué es beneficioso hacerlo.

\section{Palabras clave:}

Tecnologías de la Información y la Comunicación (TIC), Espacio Europeo de Educación Superior (EEES), sociedad del aprendizaje, sistemas de enseñanza y aprendizaje, docencia universitaria.

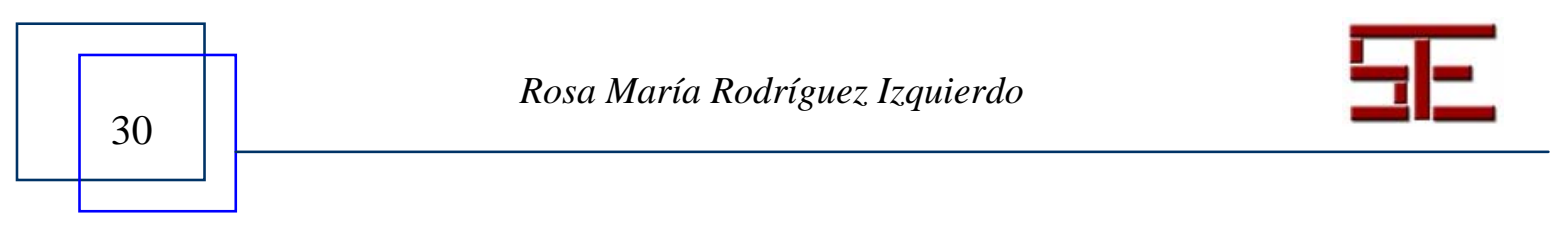




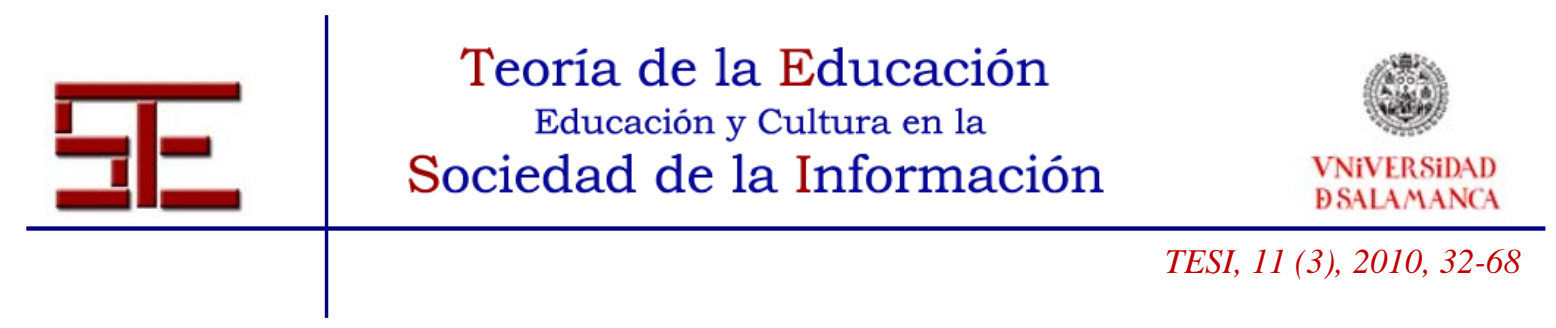

\title{
THE IMPACT OF ICT IN THE TRANSFORMATION OF UNIVERSITY TEACHING: RETHINKING THE MODELS OF TEACHING AND LEARNING
}

\begin{abstract}
:
In the last few years the discussion on the use of ICTs in higher education has turned into a key issue. In higher education, ICTs is often perceived as a catalyst for change, change in teaching style, change in learning approaches, and change in access to information. There are expectations that the existence of ICTs benefits the overall learning environment of students.

This article reviews, and aware of our great boldness, some discussions and proposals that emerge from research in relation to ICTs and education. I accept the criticism in advance to my bold claim. We do not intend to be original and admit that we have more questions than answers when we examine what is really happening in the use of ICTs in higher education.

The paper suggests that it is not technologies, but educational purposes and pedagogy, that must provide the lead, understanding not only how to work with ICTs, but why it is of benefit for them to do so.
\end{abstract}

Key words:

Information and Communication Technologies (ICTs), European Higher Education Area (EHEA), learning society, teaching and learning systems, university teaching.

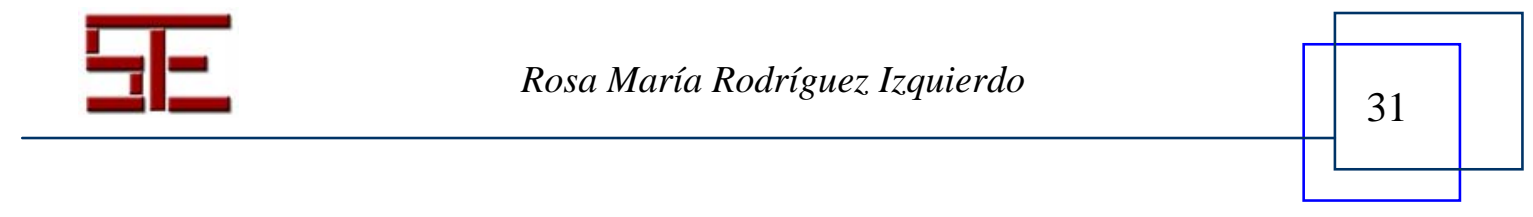




\begin{tabular}{cc}
$\begin{array}{c}\text { Teoría de la Educación } \\
\text { Educación y Cultura en la } \\
\text { VNiVERSIDAD } \\
\text { BSALAMANCA }\end{array}$ & Sociedad de la Información \\
\hline TESI, 11 (3), 2010,32-68 &
\end{tabular}

\section{EL IMPACTO DE LAS TIC EN LA TRANSFORMACIÓN DE LA ENSEÑANZA UNIVERSITARIA: REPENSAR LOS MODELOS DE ENSEÑANZA Y APRENDIZAJE}

Fecha de recepción: 28/01/2009; fecha de aceptación: 20/12/2009; fecha de publicación: 28/02/10

Rosa María Rodríguez Izquierdo

rmrodizq@upo.es

Universidad Pablo de Olavide

\section{1.- INTRODUCCIÓN}

En este trabajo intentaremos buscar las claves de una buena integración de las TIC en la educación superior. Usando mi experiencia de trabajo en la formación superior así como la base de la investigación en este campo, el artículo trata de identificar las cuestiones clave en la investigación y sugerir algunos puntos de avance.

Como afirma Bricall (2000, 456), el alcance de las TIC en la universidad abarca tres ámbitos: los contenidos, tanto en formación como en investigación; el modelo de enseñanza y el modelo de organización. En este artículo nos preguntamos hasta qué punto la incorporación de las TIC está transformando los modelos de enseñanza y aprendizaje de la educación superior.

Las universidades europeas, en los últimos años, están inmersas en una dinámica de cambio que responde a una serie de demandas donde intervienen factores políticos, económicos y culturales que afectan a diferentes aspectos contextuales, desde el nivel del aula hasta el del grupo de universidades.

La primera parte de este trabajo describe concisamente el contexto de cambios en la universidad en el que se enclava la preocupación por la aportación de las TIC. Básicamente, nos referimos a tres acontecimientos: 1) la implantación del Espacio Europeo de Educación Superior (EEES); 2) la concepción del aprendizaje a lo largo de la vida (LLL-Long Life Learning); y 3) los rápidos avances científicos y tecnológicos.

En este momento, gran parte de los cambios que se están sucediendo en la educación superior están promovidos desde la Unión Europea con la implantación del EEES ${ }^{1}$. El EEES supone, al menos potencialmente, un reto sin precedentes en la significación

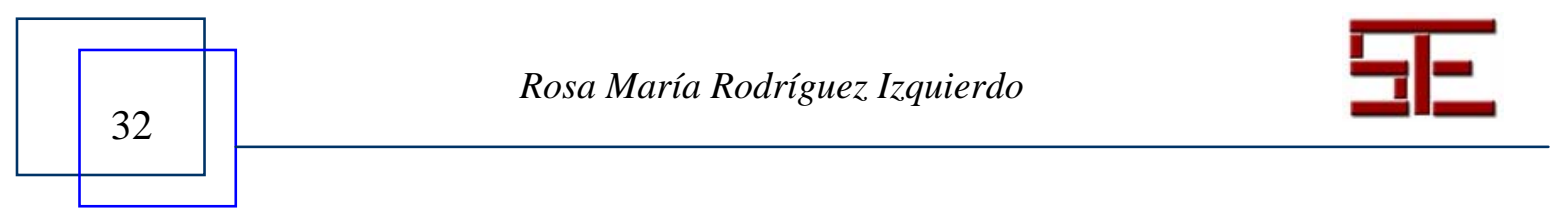




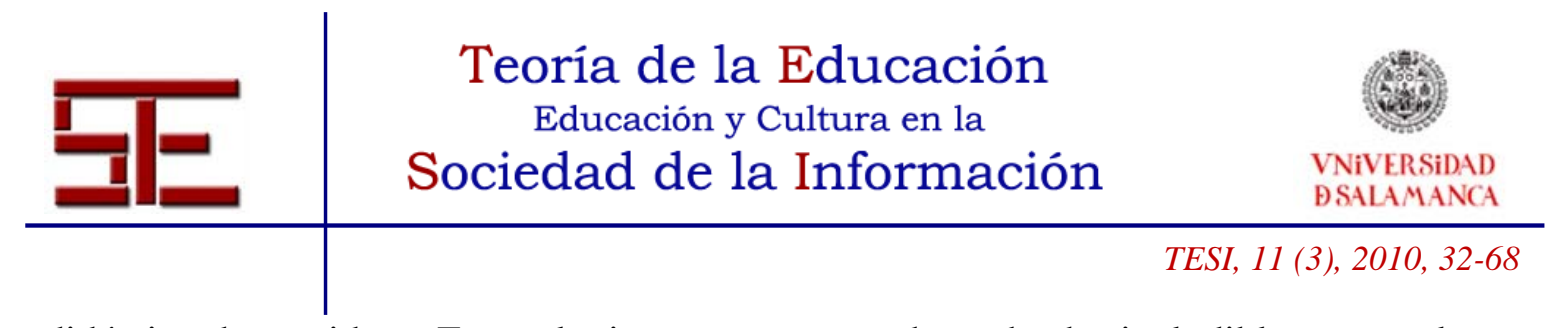

didáctica de sus ideas. En cualquier caso, se trata de un hecho ineludible y ante el que caben dos posturas profesionales, a veces, incompatibles: el pesimismo, o como lo denomina Escudero (2006) “los ojos de la posibilidad”.

Uno de los cambios sustanciales es el Sistema Europeo de Transferencia y acumulación de Créditos (ECTS). Un sistema centrado en el estudiante, que se basa en la carga de trabajo que éste necesitaría para la consecución de los objetivos de un programa. El sistema de trabajo basado en ECTS implica grandes cambios en el proceso de enseñanzaaprendizaje y, por lo tanto, en el papel del profesorado y de los estudiantes.

Desde esta concepción, parece que en la universidad contemporánea el alumnado debe aprender a aprender y el profesorado debe reaprender a enseñar (Rodríguez Izquierdo, 2003). Lamentablemente, como afirma Bain (2005), la gran mayoría de nosotros estamos mucho más preocupados por lo que tenemos o tendríamos que hacer que por lo que deberían aprender nuestros estudiantes a partir de lo que les enseñemos.

Por otro lado, es cada vez más evidente y fundamental el papel de la universidad en el desarrollo del aprendizaje continuo a lo largo de toda la vida (Jarvis, 2008). Es decir, una formación concebida como el inicio de un proceso formativo que durará toda la vida, donde el individuo precisa ser capaz de manipular el conocimiento, de actualizarlo, de seleccionar lo que es apropiado para un contexto específico, de aprender permanentemente, de entender lo que aprende, de tal forma que pueda adaptarlo a nuevas situaciones que cambian rápidamente.

En este escenario se pone de moda el conocido eslogan: Estudiar toda la vida para trabajar toda la vida. En otro tiempo uno se formaba para toda una vida, hoy día nos pasamos la vida formándonos. Como la economía mundial cambia, los nuevos puestos de trabajo están reemplazando a los antiguos de tal manera que se pronostica que la mayoría de las personas cambiarán de empleo seis o siete veces. Las personas buscan oportunidades educativas para satisfacer estas demandas. De esta manera, la universidad retoma y continúa la formación preuniversitaria y no cierra el proceso formativo sino que lo concibe como un escalón más en el continuum de aprendizaje y desarrollo profesional que durará toda la vida de los sujetos. En consecuencia, la misión de la educación superior se debe ampliar a fin de incluir estos objetivos ${ }^{2}$. A la vez, el sector tiene que hacer frente a las necesidades de estudiantes no tradicionales, cada vez más diversos (Katz et al., 1999) y dar respuesta a los requerimientos de la calidad (Harvey \& Knight, 1996). En consecuencia, la competencia entre instituciones de educación superior está aumentando rápidamente (Pedro, 2001). Entonces, ¿cómo en el siglo XXI pueden las TIC ser explotadas para dar un apoyo más flexible a una población estudiantil más diversa?

Por último, el vertiginoso avance de las tecnologías impregna la práctica totalidad de las actividades cotidianas que desarrolla el ser humano. Las tecnologías han transformado

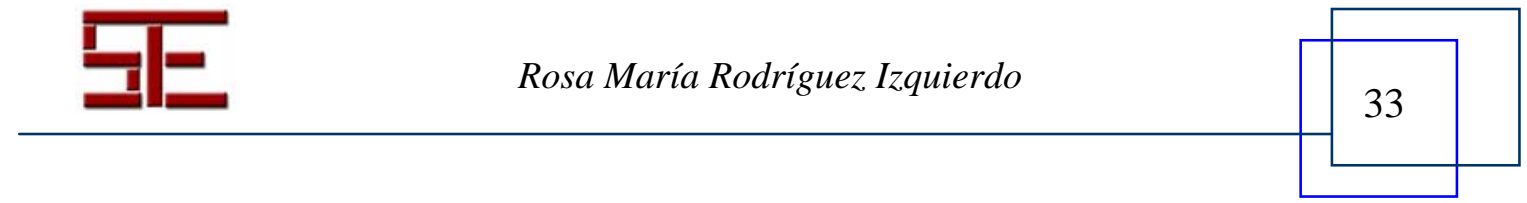




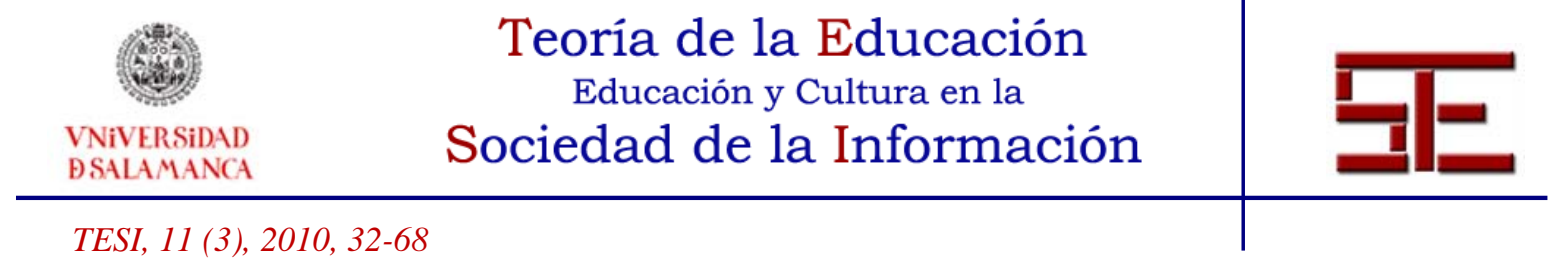

nuestro mundo casi más allá de lo que somos capaces de reconocer en nuestras vidas. En esta nueva sociedad que aún está emergiendo se han convertido en algo ineludible. Desde la invención de la imprenta no se había producido un fenómeno social y tecnológico tan importante en el área de la comunicación como el invento de Internet. El dinamismo de este fenómeno está cambiando los paradigmas socioeconómicos, la forma de trabajar, la forma de comunicarnos, la forma de acceder a la información, etc., y comienza a influir en el ámbito educativo.

Lo cierto es que la universidad, si quiere dar respuesta a estos retos, debe examinar los cambios que se están produciendo en su entorno ya que muchos de esos cambios tienen implicaciones en la forma de organizar la enseñanza universitaria propiciados por el EEES a los que hemos hecho referencia.

Sin duda, el tema de las TIC es una de las cuestiones contemporáneas que más preocupan a todos los interesados en el desarrollo de la educación. Las consecuencias de su utilización y su desarrollo son objeto actualmente de un intenso debate que incluye diferentes dimensiones, tanto pedagógicas como políticas, económicas y culturales (UNESCO, 1996).

La universidad se está transformando, indudablemente, debido a estos avances. Para Hanna (2002) los cambios y los nuevos desarrollos en la enseñanza universitaria se están sucediendo a un ritmo cada vez más acelerado debido a los avances producidos en el campo de las comunicaciones digitales globales y a la creciente sofisticación de las tecnologías educativas.

Existe unanimidad en aceptar que las grandes aportaciones de las tecnologías (informática, telemática y multimedia) se relacionan sobre todo con el fácil acceso a fuentes de información, con el procesamiento de datos y con la comunicación inmediata, sincrónica y asincrónica con otras personas. De tal manera que, en la actualidad, el acceso a la información ya no es la cuestión que preocupa, sino la gestión de los distintos saberes y cómo fomentar el deseo de saber frente a la sobreinformación circundante en la sociedad y cómo formar los marcos de referencia para procesar la información disponible. No puede suponerse que sólo porque los estudiantes sienten un alto grado de confianza en la búsqueda de la información son realmente usuarios sofisticados de la información. De hecho, no lo son (OCLC y De Rosa, 2006). El poder de Internet es que todo el mundo puede encontrar algo acerca de nada.

Frente a todos estos retos, en este artículo intentamos explorar si las TIC pueden ser uno de los elementos clave que ayuden a las transformaciones requeridas a la universidad. El tiempo en el que nos ha tocado vivir nos obliga a construir un pensamiento crítico sobre ellas y a examinar algunas cuestiones fundamentales.

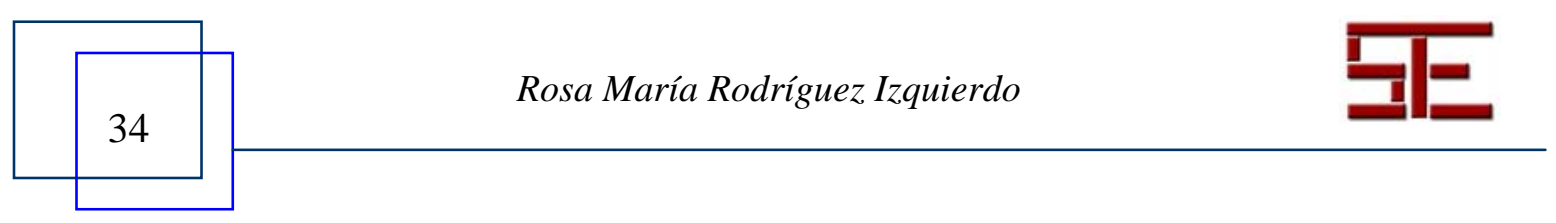




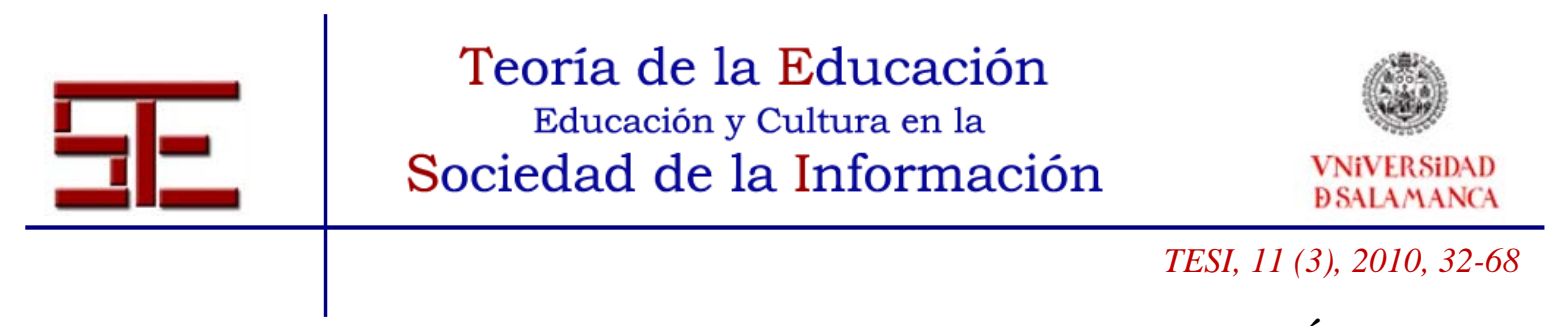

\section{2.- LA LENTA Y DESIGUAL PERO INEVITABLE INCORPORACIÓN DE LAS TIC A LA EDUCACIÓN SUPERIOR}

El uso de la tecnología como herramienta de enseñanza no es una novedad. Cada nueva tecnología que ha aparecido en la sociedad ha sido probada y utilizada en educación. Las mayores expectativas en relación con las TIC a menudo pueden ser encontradas en el área de la enseñanza y el aprendizaje (Bates, 2000). Durante más de 50 años los estudios de investigación han examinado cómo el uso de estas herramientas afecta al aprendizaje. La expectativa de hacer más sólido el aprendizaje utilizando la tecnología se ha ido propugnando desde el advenimiento de la radio a la televisión.

Desde principios del decenio de 1990, el uso de las TIC en la enseñanza superior dio un gran salto hacia delante produciéndose un incremento generalizado de éstas. Esta revolución de las comunicaciones fue dirigida por el desarrollo de Internet que proporciona una plataforma de correo electrónico, seguido de cerca por las tecnologías móviles. En la segunda mitad del decenio, la "C" fue añadida por pedagogos al acrónimo “TI” con la intención de incluir la creciente importancia de la comunicación a los aspectos de esta tecnología.

Estos sistemas han continuado desarrollándose, haciéndose más rápidos, más baratos y más fáciles de usar para ser aprovechados por todos los sectores de la sociedad y la economía. Las instituciones educativas, y particularmente las universidades, han mostrado un progresivo interés en la incorporación de estas tecnologías a su actividad docente. Es cada vez más común que las universidades cuenten en sus campus con redes inalámbricas y múltiples puntos de conexión. Existe una tendencia a invertir en aplicaciones corporativas para la gestión universitaria ${ }^{1}$, en las que se incluyen plataformas de teleformación relacionadas con los procesos de enseñanza-aprendizaje, por lo que después de varias décadas y de una inversión considerable, muchas universidades están revisando su estrategia en el uso de la tecnología y haciéndose preguntas importantes tales como: ¿Nuestra inversión en tecnología ha apoyado nuestra misión y visión institucional o respondieron simplemente a una tendencia?; y ¿ha resultado en mejoras en el resultado de los aprendizajes y promovido la nueva pedagogía centrada en el alumno o tuvo poco impacto en el aprendizaje?

A pesar de que la irrupción de las TIC en la sociedad es ya una realidad palpable, su ubicuidad y su función en el mundo de los negocios en la educación superior aún no están tan claras. La retórica del cambio ha sido demasiado asociada con la función simbólica de la tecnología en la sociedad mientras que llevar esta nueva revolución a la universidad no es una tarea fácil. El diagnóstico en el que se encuentra la implantación

\footnotetext{
${ }^{1}$ Según los estudios éste es uno de los ámbitos donde se pone de manifiesto con más claridad el impacto de las TIC en la educación superior (Duart y Lupiáñez, 2005 y Tomás el al., 1999).
}

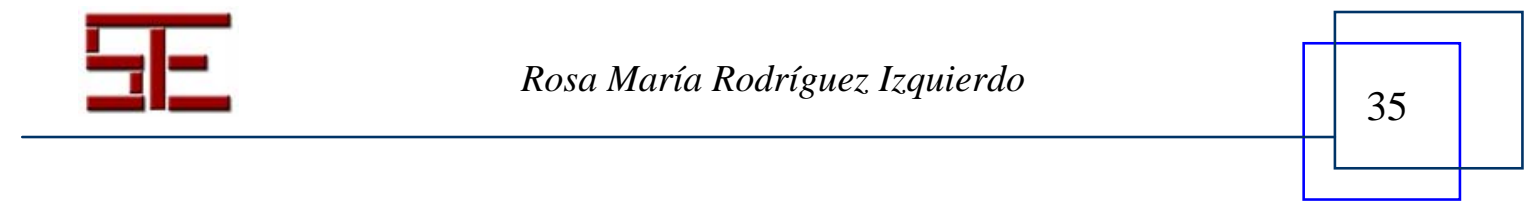




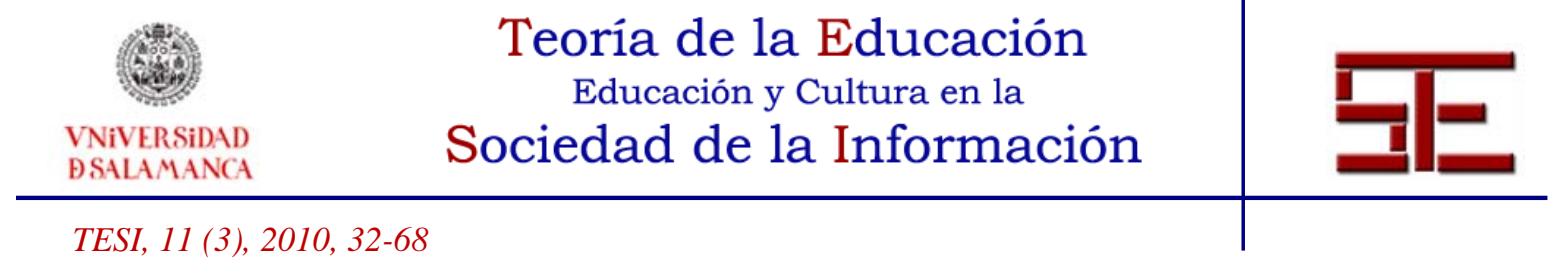

de esta tecnología como herramienta pedagógica en la educación superior dista mucho de ser unánime y generalizado. Sergún Selwyn (2007) está infrautilizada y en muchos casos sigue estando sin explotar en gran medida. Por lo tanto, las TIC, al parecer, aún tienen que encontrar su propia voz.

Existe una necesidad creciente en la comunidad educativa de explicar la desconexión entre la retórica entusiasta y la realidad ordinaria en el uso de las TIC en la universidad. Como suele ocurrir en el debate educativo, la culpa de esta disparidad se ha atribuido con frecuencia a los déficits de habilidades, motivación y conocimientos técnicos por parte de los estudiantes, del profesorado y de las instituciones educativas (Keller, 2005). Sin embargo, Selwyn (2007) trata de distanciarse de los habituales discursos "de la deficiencia” y de explicar el (no) uso de las TIC en la educación superior sin pasar por alto los elementos sociales, económicos, políticos y culturales en el uso de la tecnología. En particular, propone un examen crítico de la construcción social de la educación superior y la "tecnología" en sus diferentes niveles desde las acciones del gobierno y de organismos comerciales hasta las experiencias de los estudiantes. Con esto en mente, considera las relaciones sociales más amplias que sustentan la integración de las TIC en las universidades e intenta, por tanto, explicar de alguna manera la naturaleza restrictiva y decididamente no transformativa del uso formal de las TIC en la educación superior contemporánea.

Laurillard (2002, prefacio) intenta exponer alguna de las razones por las que en la universidad se reduce el potencial pedagógico que pueden ofrecer las TIC. Una de las explicaciones es que muchas de las actuales generaciones de profesores universitarios no han aprendido a través de la tecnología por lo que en la práctica se desarrollan lentamente y en la teoría casi nada. Laurillard también aporta reflexiones interesantes sobre la falta de marcos conceptuales y la variabilidad de profesores con respecto a la utilización de las TIC.

En este sentido, también Seale et al. (2003) han intentado aportar sobre este asunto. Al igual que Mishra y Koehler (2006) esbozan un modelo conceptual para el análisis de la práctica pedagógica que incluya las TIC. Un punto clave es el hecho de que las tecnologías actuales cambian rápidamente en comparación con anteriores tecnologías también aplicadas a la educación. Esto tiene varias consecuencias como que los profesores no tienen tiempo para aprender de la experiencia y muestran dificultad para mantenerse al día, lo que hace que puedan sentirse reacios a invertir tiempo y esfuerzo en las últimas tecnologías. Este continuo cambio puede dar lugar a "la alienación de las TIC y provocar ansiedad" en algunos profesores. Además, el cambio continuo no ofrece estabilidad para la investigación de la práctica que ha tendido a ser limitada.

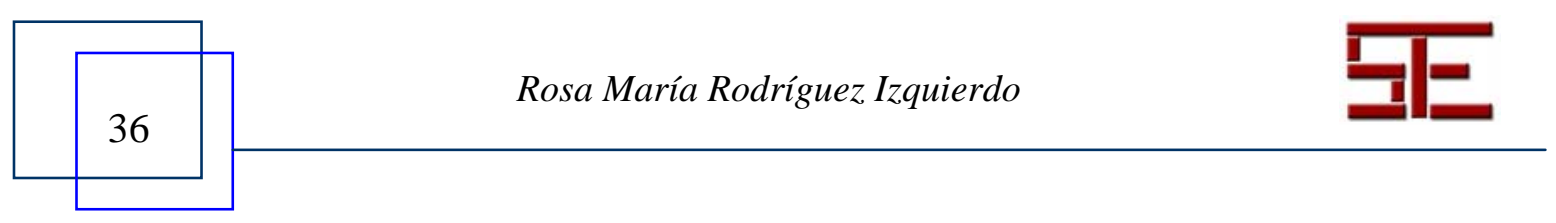




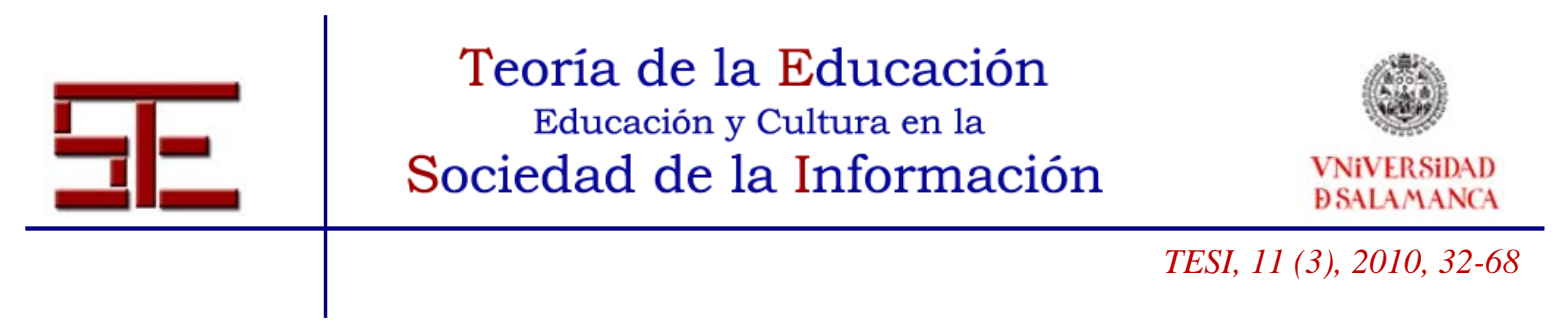

Oliver (2003) sostiene un segundo aspecto clave del debate. Se trata de la tensión entre la tecnología y la pedagogía. Después de muchos años de políticas internacionales y de grandes inversiones en las TIC, la pedagogía sigue siendo un elemento ajeno en las aplicaciones tecnológicas en la educación superior. La mayoría del software utilizado es diseñado con fines comerciales en lugar de uso educativo. El peligro es que la tecnología es el motor de la pedagogía y alienta a una "transmisión" en los entornos de aprendizaje virtual.

Si echamos una mirada a cualquier manual de pedagogía donde se definan los elementos considerados clásicos o tradicionales de la educación, seguramente nos sorprenderá encontrar que muchos de ellos, la gran mayoría, siguen estando vigentes en los denominados entornos virtuales de enseñanza o en la educación superior actual aun cuando se haga un uso importante del ordenador como recurso didáctico de primer orden.

Cada vez conocemos más de los procesos que conducen al aprendizaje en los humanos, en este sentido hay una cierta convicción de que el resultado de todo aprendizaje es fruto de una actividad directa y personal del aprendiz. Pero si pudiéramos ver lo que sucede en la mayoría de las aulas universitarias españolas comprobaríamos que la metodología que se sigue utilizando está muy alejada de esta concepción ${ }^{3}$.

Las investigaciones recientes indican que el uso y la aplicación de las TIC es un proceso en dos etapas donde la primera fase incluye la racionalización de las rutinas administrativas, la comunicación y transmisión de conocimientos, sin graves repercusiones en la pedagogía y la enseñanza de las tradiciones (Vuorikari, 2004). Es sólo en la fase siguiente en la que las estructuras pedagógicas y las formas de pensar pueden ser transformadas. Estos hallazgos parecen relevantes también para el momento presente. Sin un enfoque en las necesidades personales de los que realmente van a utilizar e integrar las TIC en el trabajo en las instituciones de educación superior, nos podemos imaginar que muchas instituciones tienen grandes dificultades para superar la primera fase.

Las instituciones de educación superior son bien conocidas por su capacidad para proteger las actividades tradicionales básicas de la injerencia externa, lo que puede explicar la falta de efectos directos de las TIC. "La tiza y la palabra" siguen siendo el uso dominante y legítimo en muchas instituciones. En otras palabras, hay razones para creer que en la práctica actual de la educación superior las iniciativas y las actividades TIC suelen ser más fragmentadas y menos sistemáticas de lo que generalmente se reconoce y que esta situación es un típico punto de partida en las instituciones de enseñanza universitaria para intentar adaptarse más sistemáticamente a las promesas de las TIC en la enseñanza y el aprendizaje.

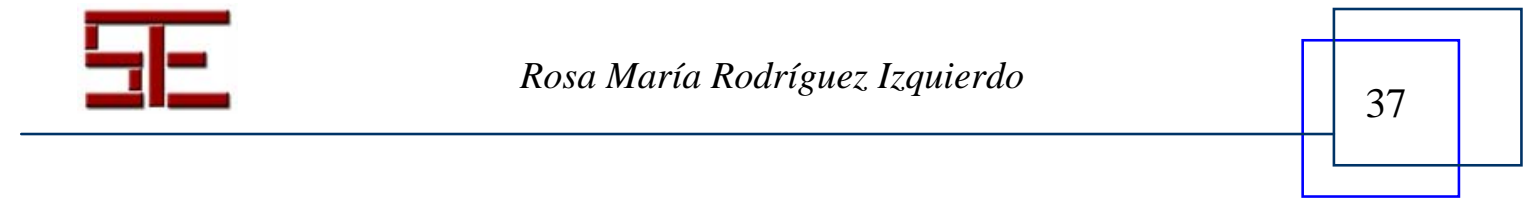




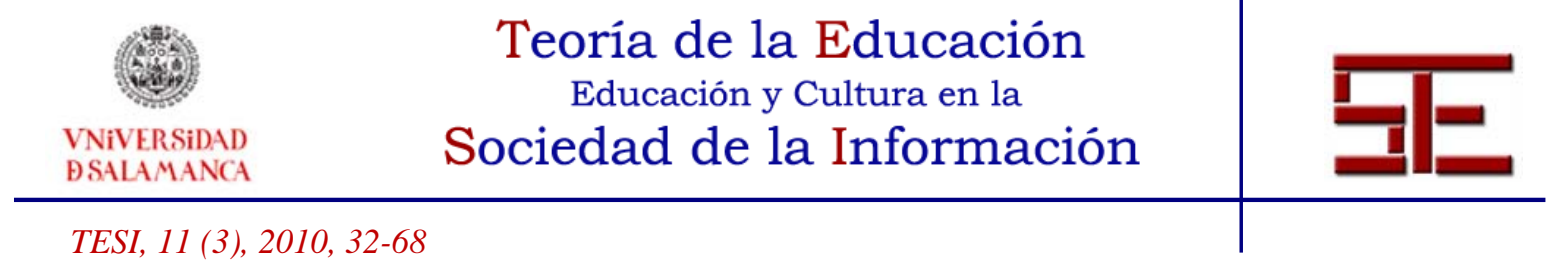

Por otro lado, las universidades son instituciones importantes que están sujetas al cambio institucional de sus propias reglas y encuentran sus propias barreras. Barone (2001) y Twigg (1999) han documentado múltiples formas en que las instituciones educativas se resisten a la transformación tecnológica. Ertmer (1999) ha señalado que estas barreras generalmente se dividen en dos categorías. De primer orden son los obstáculos externos a la persona y el puesto de trabajo y normalmente la participación de los recursos disponibles, por ejemplo, la falta de equipo, el tiempo o la falta de formación. Si bien estas barreras pueden ser muy frustrantes, son relativamente obvias y fáciles de abordar. Sin embargo, la eliminación de ellas no logra un cambio de segundo orden, porque los obstáculos que pueden no ser tan evidentes para los individuos implicados, por lo general, permanecen. Las de segundo orden son las barreras internas a las personas y sus funciones profesionales y, a menudo, tienen que ver con las creencias acerca de la enseñanza y las tecnologías, las prácticas establecidas y la falta de voluntad para el cambio. Para llevar a cabo el cambio institucional dentro de una universidad es necesario hacer frente tanto a los obstáculos de primer orden como a los de segundo orden.

\section{3.-RESULTADOS DE LA INVESTIGACIÓN SOBRE EL IMPACTO DE LAS TIC EN LA ENSEÑANZA SUPERIOR}

La literatura académica anglosajona es pródiga en la publicación de trabajos, tanto teóricos como prácticos, en el uso de las TIC en la enseñanza superior. Pedagogos, políticos, familias y alumnos claman por la incorporación de las TIC al mundo educativo.

Debemos afirmar que un análisis profundo de la situación no permite, hasta ahora, hacer comentarios demasiado concluyentes. Con respecto a las consecuencias pedagógicas del uso de las TIC, y a pesar de la intensa pasión que ponen tanto los militantes de su utilización como sus oponentes, el estado actual de la cuestión no permite formular conclusiones categóricas. Los estudios sobre la eficacia y la eficiencia de la utilización integrada de las TIC en la educación universitaria tampoco han llegado siempre a conclusiones optimistas. En las secciones siguientes se presentan algunos resultados de la investigación.

\section{1.- Preguntas útiles y preguntas inútiles}

Las posibilidades de los servicios telemáticos y su integración con la informática, la telefonía, el teletexto, etc., nos obligan a reconsiderar algunas cuestiones específicas en torno a la universidad. ¿Está el uso de las TIC cambiando verdaderamente el modelo de enseñanza y aprendizaje universitario? Junto a esta cuestión aparecen otras como: ¿A qué nivel está afectando realmente la introducción de las TIC la práctica pedagógica? ¿Cuáles son las conclusiones de la investigación sobre el uso pedagógico de las TIC? ¿Hay lagunas en la investigación que requieren mayor investigación? ¿Qué perspectivas

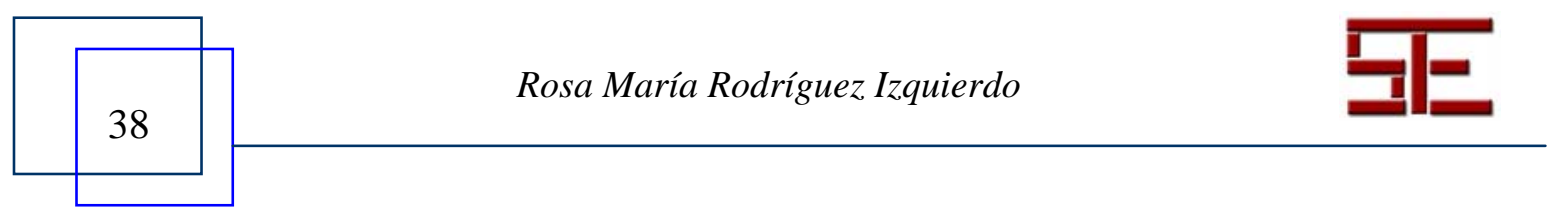




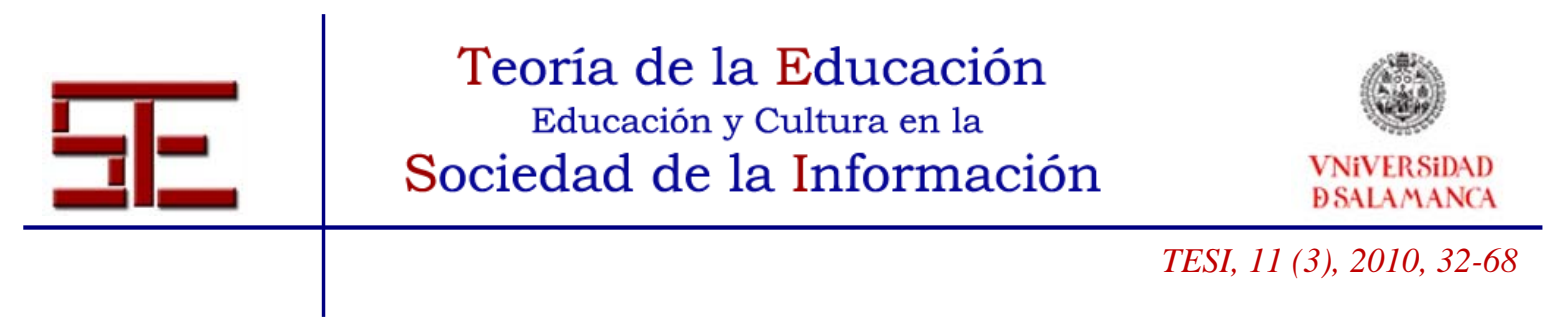

y alternativas sugiere la literatura para el futuro? ¿Está cambiando el uso de las TIC la manera de entender la educación, el propio concepto de educación superior? ¿Cuáles son las condiciones necesarias para su efectividad educativa? ¿Aportan las TIC algún valor agregado al aprendizaje? ¿Tiene el uso de las TIC incidencia en los procesos educativos propiamente dichos? ¿Cómo se redefinen las relaciones dentro del aula cuando estamos hablando de espacios virtuales, en muchas ocasiones “colgados” en la red?

Es importante responder a estas preguntas, porque existe un cierto determinismo sobre los avances de la técnica y la ciencia. Muchas universidades han respondido con una tecnología más omnipresente. La idea subyacente en la mayoría de las iniciativas de hacer las tecnologías más visibles ha sido que el mero acceso a la tecnología daría lugar a su uso directamente. Se asume que, puesto que las máquinas están ahí, han de usarse y aprovechar al máximo sus utilidades, pero ello carece de sentido, si dentro del sistema educativo no está claro lo que se quiere obtener con la introducción de las TIC, ahora y en el futuro.

Como afirma Ehrmann (1995) hace falta el mismo esfuerzo para responder a una cuestión útil como a una inútil. Por tanto, la búsqueda de información útil acerca de la tecnología se inicia con una rigurosa búsqueda de las preguntas adecuadas. Este autor analiza algunas preguntas inútiles, unas cuantas preguntas más útiles y los resultados que han dado lugar y un tipo de cuestiones que nos tenemos que seguir haciendo acerca del uso próximo de las TIC en el aprendizaje.

En primer lugar, analiza las malas cuestiones en torno al uso de las tecnologías en la enseñanza superior. Este primer grupo de preguntas inútiles busca respuestas a preguntas universales acerca de la eficacia comparativa de la enseñanza. Este tipo de preguntas evaluativas están redactadas en términos como los siguientes: ¿las TIC realizan un mejor trabajo en la enseñanza que los métodos tradicionales?

Esta cuestión asume que la educación funciona algo así como una máquina y que cada universidad es una versión ligeramente distinta de la misma máquina "ideal". Preguntas como éstas utilizan la frase "métodos tradicionales" para simbolizar algunos métodos ampliamente practicados que tienen resultados previsiblemente aceptables. Si la tecnología obtiene un mejor rendimiento que los métodos tradicionales, tales preguntas implican que "todo el mundo" debería utilizarlas.

La investigación sobre las TIC ha estado demasiado tiempo atrapada en un paradigma de comparaciones simplistas. Hasta ahora la investigación se ha centrado en dos tipos de cuestiones. Las primeras están relacionadas con la naturaleza de la comparación y en especial con el trabajo de las simplificaciones que normalmente se suponen en la inves-

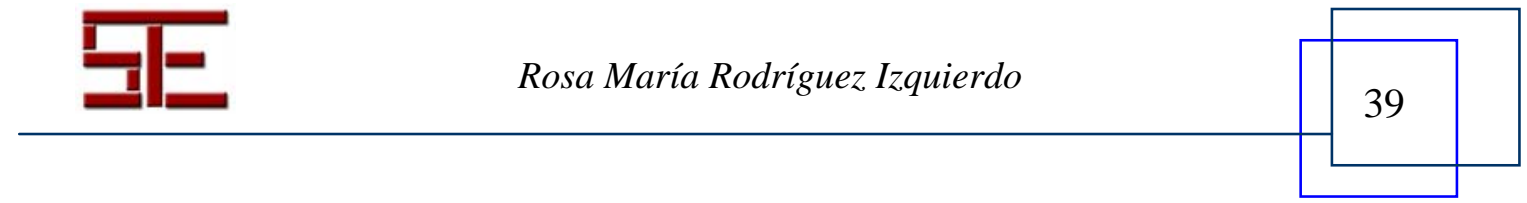




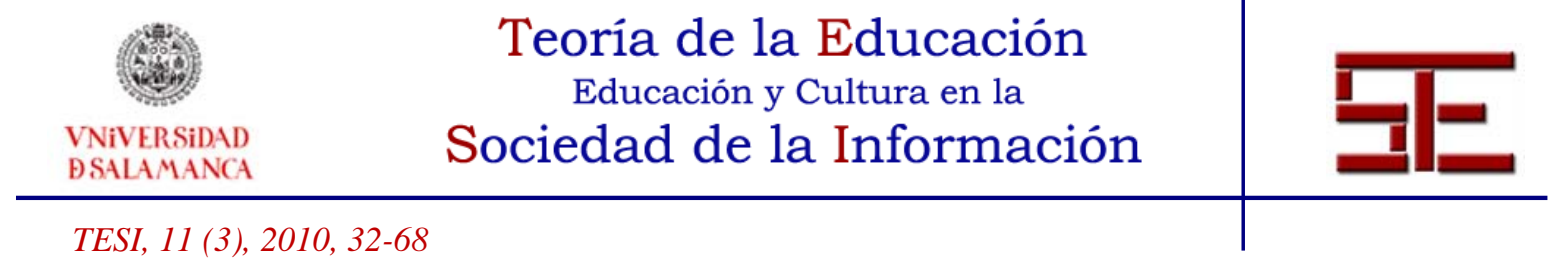

tigación comparativa. Las segundas están relacionadas con un cambio de perspectiva que va desde la innovación educativa al aprendizaje del estudiante. ¿Cómo experimentan los estudiantes universitarios el uso de las TIC en sus estudios y en su aprendizaje? En pocas palabras, ya no parece muy productivo o intelectualmente defendible separar los aspectos tecnológicos del aprendizaje, la enseñanza, la educación y el diseño. Se necesita una perspectiva más holística en la investigación del uso pedagógico de las TIC.

También queremos señalar que esta mentalidad ha estado caracterizada por un interés en la comparación y la sustitución en lugar de en el análisis y la integración. Cada innovación tecnológica ha ido acompañada de preguntas como si es mejor que la que existe, en lugar de preguntas acerca de cómo debe integrarse con lo que existe. Las preguntas acerca de la integración son inicialmente más complejas que las cuestiones relativas a la comparación. Sin embargo, creemos que la investigación que únicamente se ocupa de cuestiones de comparación está haciendo caso omiso de toda una serie de cuestiones prácticas difíciles pero investigables cuya resolución es esencial para el éxito de la asimilación de una tecnología o práctica innovadora. Esta obligación de comparar y discutir la producción de datos comparativos esta acosada por los procesos de simplificación intelectual en el que algunas cosas pasan a un primer plano mientras otras se quedan más en el fondo. Resulta que la calidad del aprendizaje está rara vez en primer plano y que el trabajo que los estudiantes tienen que realizar para hacer de la innovación un éxito a menudo desaparece en el fondo.

Da la impresión de que el carro ha sido colocado delante de los bueyes. No cabe duda de que las TIC pueden cambiar los conocimientos y la manera de acceder a ellos. Pero lo que necesitamos saber es ¿qué tipo de conocimientos necesitamos en el siglo XXI?

\section{2.- Las TIC y los métodos de enseñanza y aprendizaje}

La necesidad de un cambio profundo en los modos de enseñanza no es algo nuevo en educación. La cuestión es ver si el impacto y la transformación que hoy están produciendo las TIC en la enseñanza y el aprendizaje abren nuevas concepciones para la enseñanza.

Hace varias décadas, cuando los educadores comenzaron a pensar seriamente acerca del uso de las nuevas tecnologías del momento en la enseñanza, se oían cosas como que la televisión arruinaría el aprendizaje y que los ordenadores revolucionarían la instrucción. En otras palabras, se preguntaban si una tecnología puede enseñar sin especificar nada acerca de los métodos de enseñanza implicados. Ciento treinta años antes en Grecia se había oído el mismo debate sobre el impacto de la palabra escrita en la educación basada en el diálogo.

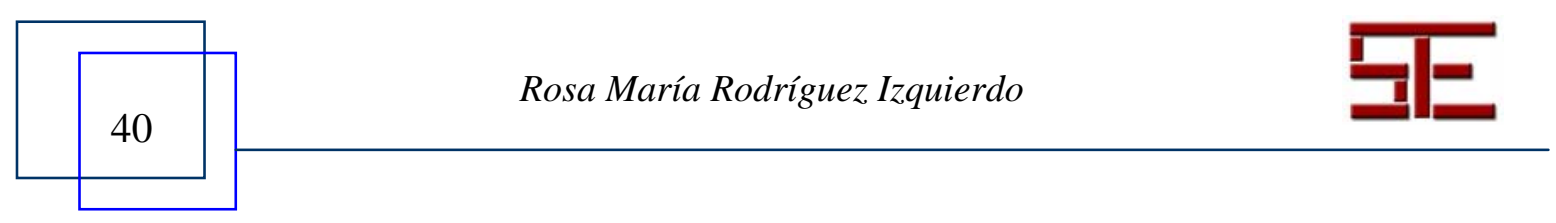




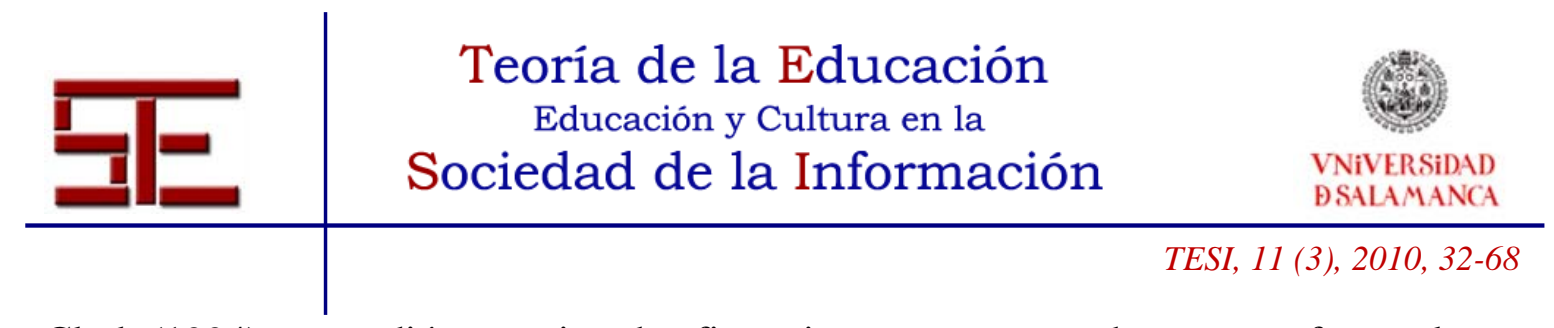

Clark (1994) respondió a ese tipo de afirmaciones argumentando que, en efecto, el medio no es el mensaje. Los medios de comunicación y otras tecnologías son tan flexibles que no determinan los métodos de enseñanza y aprendizaje. La investigación, Clark dijo, debe centrarse en los métodos de enseñanza-aprendizaje y no en las preguntas de los medios de comunicación.

Los estudios de Clark provocaron una avalancha de respuestas ya que parecía estar diciendo que la tecnología era irrelevante. Lo que parece claro hoy en día es que cualquier tecnología no es irrelevante. Toda tecnología puede ser buena o ser utilizada pobremente para apoyar un determinado método de enseñanza-aprendizaje. Ciertamente, puede haber una elección de tecnologías para la realización de una determinada tarea docente pero no es necesariamente una gran elección. Existen varias herramientas que pueden utilizarse para fijar un tornillo, pero la mayoría de las herramientas no pueden hacerlo y algunas son mejores para hacerlo que otras. Lo que Clark intentaba sugerir es que deberíamos centrar la investigación sobre aquellas tecnologías que son las mejores para apoyar los mejores métodos de enseñanza y aprendizaje.

Después de desarrollar investigaciones durantes años y de ser preguntado en numerosas ocasiones sobre si el uso de las tecnologías incrementa el aprendizaje y la motivación en los estudiantes, Clark subrayaba que no existen conclusiones relevantes en ninguna dirección.

El mensaje de Clark sigue siendo relevante hoy en día. Demasiados gestores universitarios asumen que si los profesores conocen el "hardware" (ordenadores, plataformas de enseñanza y otros medios) sabrán hacerlo útil para mejorar el aprendizaje de los estudiantes, asumiendo que si los profesores cuentan con este material fácilmente, de manera casi automática y rápida, cambiarán sus estrategias de enseñanza aprovechándose de las ventajas de estos medios. Así pues, los presupuestos suelen incluir la tecnología pero casi no hay dinero para ayudar a los profesores a actualizar sus programas de enseñanza. Los trabajos de Clark sostienen que el medio utilizado para facilitar el contenido nunca es el factor decisivo. Más bien sustenta que las estrategias y técnicas empleadas por el profesor y el alumno son la clave, no la tecnología que se utilice. Clark $(1994,26)$ afirma que "todos los métodos... podrán ser suministrados por una variedad de medios. Es el método el que es el ingrediente activo".

La integración de las TIC en modelos formativos no adecuados no solo no mejora el aprendizaje sino que lo empeora incrementando la carga de profesores y estudiantes. Como afirma J. Martínez (2004): "El alumno sigue siendo el mismo espectador que era antes y además ahora está solo, con un artefacto tecnológico por medio (el ordenador) y las autopistas de la información que rara vez se comportan como tales”.

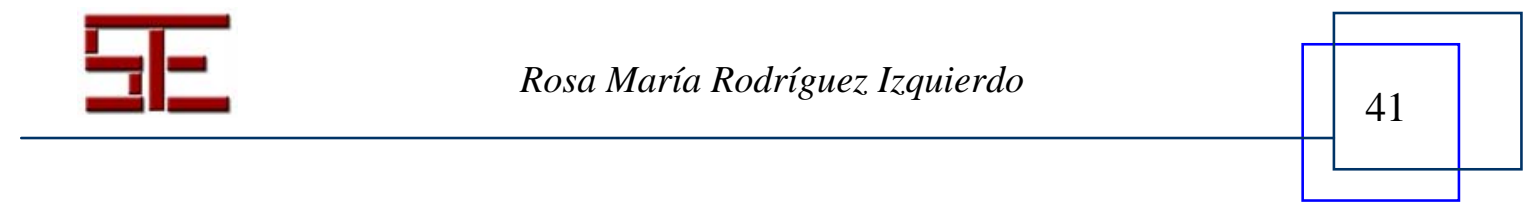




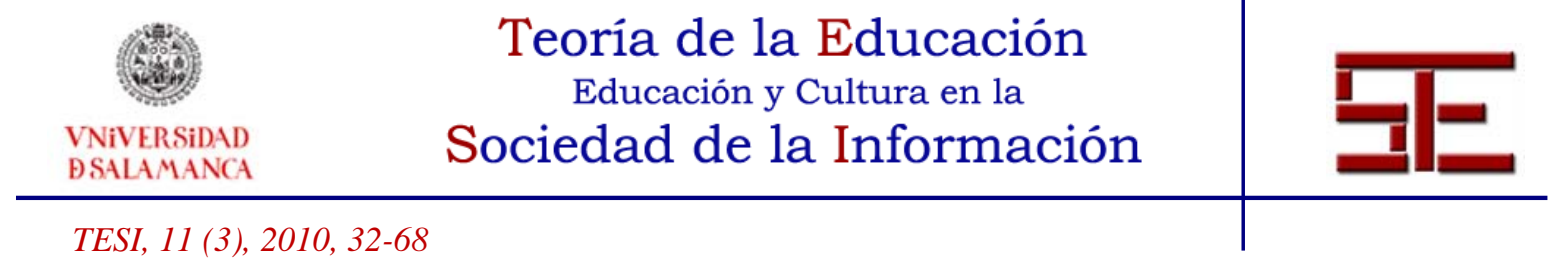

Aunque esto podría verse como una provocación, tenemos que reconocer que casi todo lo que los estudiantes aprenden hoy fue aprendido por sus predecesores sin la ayuda de las TIC. Pero, como las TIC se desarrollan y se convierten en parte de los procesos de aprendizaje, pensamos que el desarrollo de $\operatorname{Kozma}(1994,11)$ sobre la opinión de Clark tiene más sentido al afirmar que: "En un buen diseño, los medios y los métodos se confunden inexorablemente... Uno no puede simplemente reemplazar un medio por otro... y mantener todo lo demás constante...". Este argumento plantea la pregunta de qué mejoras han proporcionado algunas tecnologías o cuál es el valor agregado que aportan las TIC al aprendizaje. Haríamos bien en recordar las promesas hechas en nombre de la radio, la televisión y el vídeo para la educación. ¿Revolucionaron el aprendizaje? ¿Por qué las TIC van a ser diferentes?

Russel (1997) publicó su famoso libro The no significant difference phenomenon que ha dado lugar a todo un movimiento en Estados Unidos con este nombre. La teoría de Russel es que cada innovación tiene éxitos y fracasos pero pocos han mostrado diferencias significativas en las mediciones del aprendizaje. Twigg (1999) apoyó a Russell en que los educadores deben centrar la atención en el aprendizaje efectivo y no en la tecnología.

Hasta ahora pocos evaluadores e investigadores han prestado mucha atención a las estrategias educativas en el uso de las tecnologías. Demasiado a menudo han sido víctimas del "rapto" de las tecnologías. La aparición en las instituciones de educación superior de estudiantes adultos puede ser un motivo poderoso para cambiar las estrategias y para examinar su importancia en el aprendizaje.

Parece que estos autores apoyan la idea de que las TIC, como tales, no aportan gran cosa ni al proceso de enseñanza-aprendizaje ni en términos de calidad ni de eficiencia. Es decir, podríamos afirmar que las TIC no pueden impactar positivamente la calidad del aprendizaje si en la filosofía del diseño de enseñanza y aprendizaje no se aprovechan plenamente las posibilidades que ofrecen dichas tecnologías (Wiske, 2005; Jonassen et al., 2008). Las TIC no son más que medios y recursos que podemos utilizar en el proceso didáctico. Cómo las utilicemos, para qué y en qué contexto es lo que hace que tengan una incidencia u otra.

\section{3.- ¿Transformación o revolución?}

En el 2001 se reunieron en Washington DC 350 líderes educativos y académicos para discutir el impacto de Internet sobre la educación superior: ¿es una transformación o una evolución? Ello da cuenta del alcance e interés de las TIC. ¿Por qué Internet y sus tecnologías asociadas si no cambian nada se han asimilado tan rápidamente en comparación con otras tecnologías?

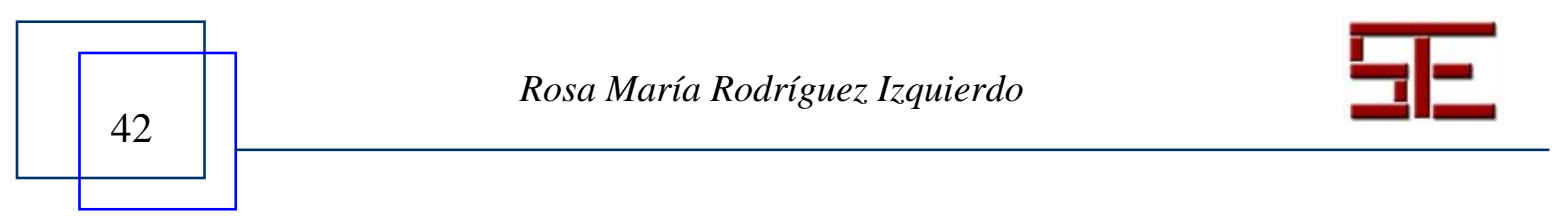




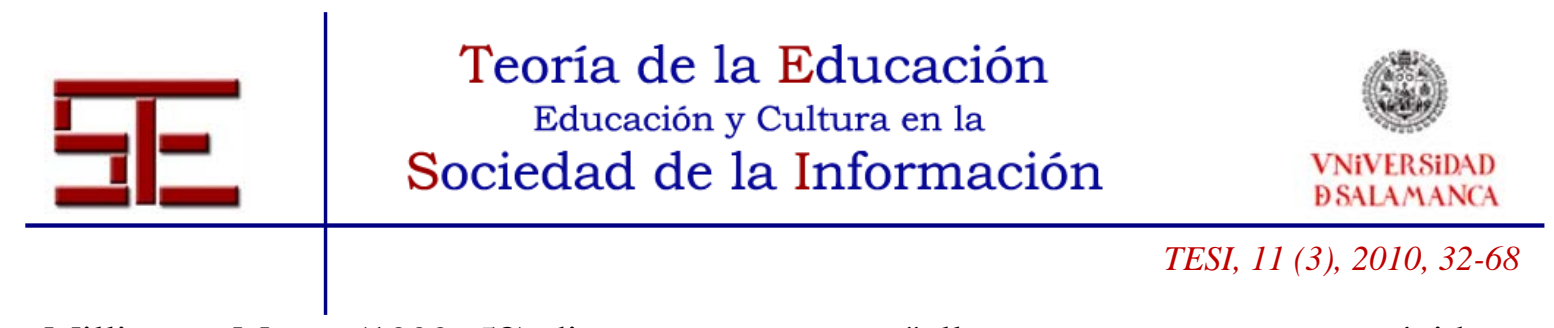

Milliron y Myers $(1999,58)$ dicen que es porque "ellas suponen un aumento rápido y fácil de la capacidad del profesor para ayudar a los estudiantes a realizar conexiones con el contenido, el contexto y la comunidad resultando, en general, en experiencias de aprendizaje más poderosas”. No obstante, reconocen que Internet no ha cambiado lo esencial en los procesos de enseñanza-aprendizaje en la educación superior.

Advierten que un elemento en la transformación de la educación han sido los avances en la digitalización. Palabras, sonidos, imágenes fijas y en movimiento pueden ser almacenadas, integradas, transmitidas y presentadas en los medios digitales para facilitar su uso y reutilización, mientras que la comunicación a través de los ordenadores y las telecomunicaciones se está generalizando. Cada vez más, los aspectos de la enseñanza y el aprendizaje están siendo mediados a través de las TIC tanto dentro como fuera de los campus.

El tema es que aunque hubiera una diferencia significativa en el aprendizaje cuando se usan estos elementos, apenas del 10 al 20 por ciento del profesorado utiliza estas herramientas. De hecho, algunos investigadores señalan que la asimilación de la tecnología es tan lenta que llevó 30 años que el proyector llegara al aula universitaria (Milliron \& Miles, 1999).

Por el contrario, Kulik y sus colegas (1991) resumieron la gran cantidad de investigación acerca del uso educativo del software. Reanalizaron los datos de un gran número de pequeños estudios con el fin de extraer conclusiones más generales. Sus hallazgos básicos fueron que la utilización de algún tipo de software en la enseñanza se traduce en una mejora sustancial en los resultados del aprendizaje y en la velocidad de los mismos. Esta instrucción funciona mejor, por supuesto, en áreas donde el ordenador puede diferenciar mejor entre una respuesta correcta o incorrecta, por ejemplo, en ejercicios de gramática o de matemáticas. Pocos otros métodos de enseñanza han demostrado resultados tan consistentes en el propio ritmo de aprendizaje.

Sin embargo, la noticia no es del todo buena. Los estudios como los analizados por Kulik y sus colegas se han centrado únicamente en el valor educativo del software, no en los factores que influyen en su viabilidad. El software destinado al uso educativo se disipa a menudo sin cumplir su promesa revolucionaria.

Un grupo bajo la dirección de Morris (1994) quería entender por qué unos pocos paquetes de software habían resultado viables mientras que muchos otros no lo eran. Para ello, analizaron paquetes de software que ya habían demostrado no sólo el valor (el poder educativo) sino también la viabilidad (su uso durante muchos años), puesto que si el software no es utilizado ampliamente por muchos profesores durante muchos años es

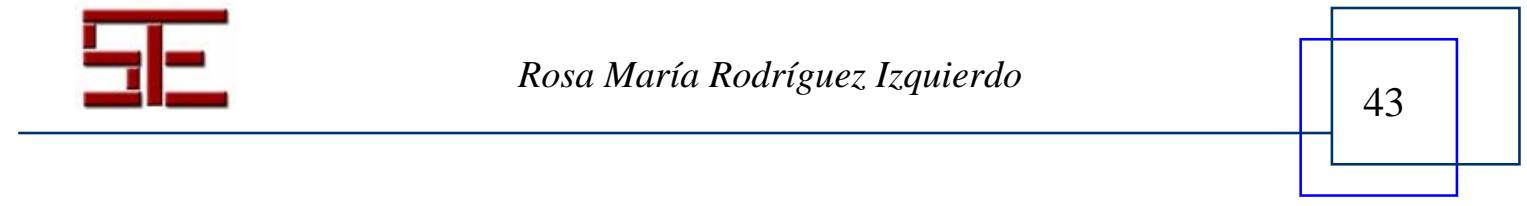




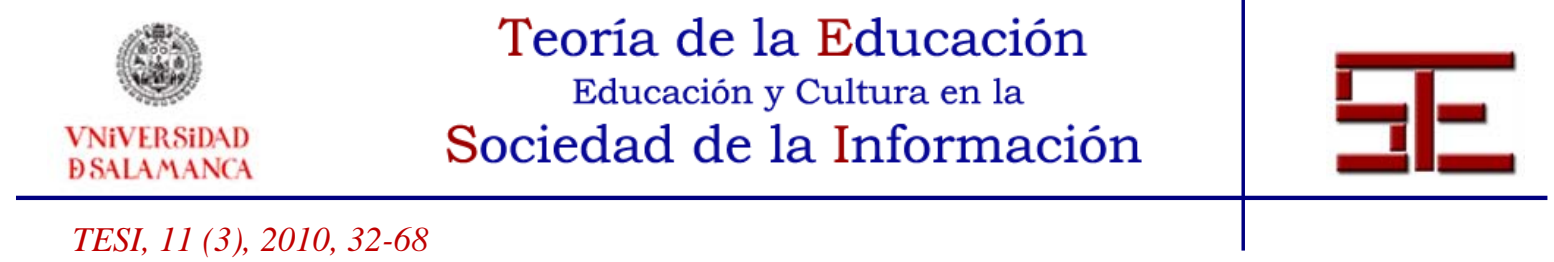

poco probable que fomente una mejora duradera en la forma en que uno o más cursos se imparten.

Tal vez la conclusión más importante a la que llegaron fue que, generalmente, lleva años el desarrollo de programas curriculares y su amplia aceptación ulteriormente. Hay muchas razones para ello. Los servicios de apoyo a menudo carecen de fondos, así que el profesorado no está seguro de qué hardware y software está en funcionamiento y disponible de manera constante. El cambio de un curso implica cambios de materiales, creación de nuevos tipos de tareas y propuestas en la formas de evaluar el aprendizaje de los estudiantes. Es casi imposible para un docente aislado encontrar el tiempo y los recursos para hacer todas estas cosas y para tomar todos estos riesgos. Pocas instituciones proporcionan los recursos y las recompensas necesarias al profesorado para tomar tales riesgos. Por estas y otras razones, el ritmo de los cambios curriculares es lento.

También descubrieron que cuanto más revolucionario es el software más ardua es la tarea de conseguir una masa crítica de usuarios. Para grandes piezas de software curricular, el tiempo que transcurre desde la concepción hasta el amplio uso puede llevar diez años o más. Lamentablemente, mucho antes de que el software curricular haya tenido un alcance amplio en su uso, los sistemas operativos de los ordenadores y las interfaces han cambiado para entonces. En lugar de ser revolucionario el software comienza a quedarse obsoleto. Su uso, en lugar de crecer comienza a disminuir. La falta de uso desalienta a los financiadores y editores en vez de invertir en la creación de la versión 2.0. El creador original también pierde a menudo el interés. Así muchos paquetes valiosos de software curricular mueren sin nunca cumplir sus promesas.

Eso no significa que el software no se utilice para el aprendizaje. Irónicamente, mientras que el software diseñado para el aprendizaje ha tenido dificultades para encontrar un mercado, la mayoría del software utilizado para el aprendizaje no fue diseñado para ese fin. Por tanto, uno de los problemas en la utilización pedagógica de las TIC es que escasamente existen materiales pedagógicos propiamente dichos. Existe una gran cantidad de documentación que puede ser utilizada de manera pedagógica si el profesorado lo sabe hacer pero lo que más existe es información inconexa que el profesor sólo puede proponer como recurso didáctico si tiene una correcta preparación para hacerlo.

Las TIC si se usan de manera absolutamente tradicional, nada constructiva, simplemente para realizar actividades y prácticas repetitivas que tienen poco que ver con la innovación y el cambio educativo no responden al reto de transformar los procesos educativos. Y, hasta ahora, la tecnología ha sido vista como un añadido a un conjunto de prácticas educativas tradicionales.

Por supuesto, hay ejemplos de la más radical y profunda reconceptualización de las relaciones entre el uso de la tecnología y los resultados del aprendizaje, muchas de las

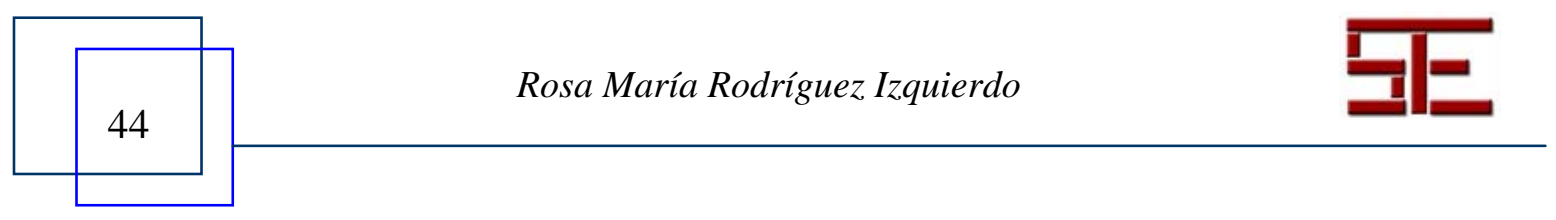




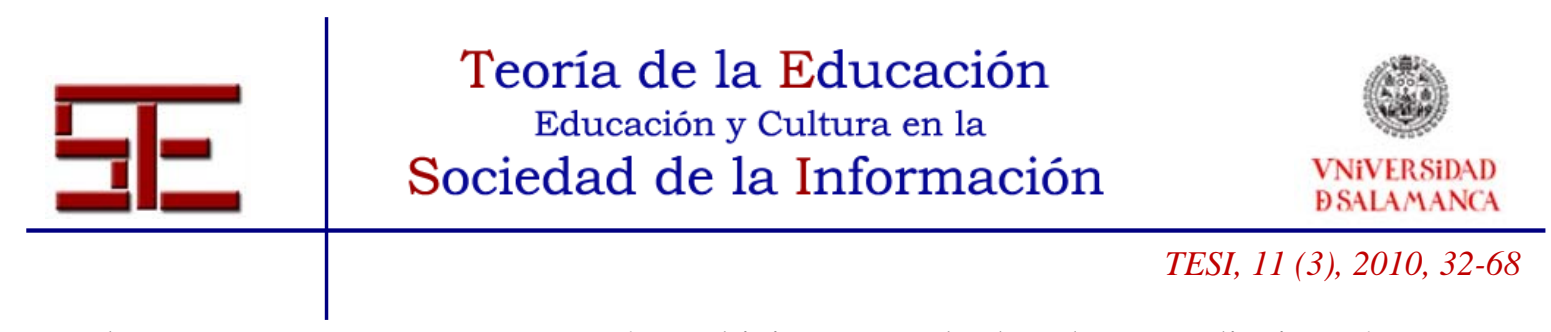

cuales se centran en nuevos y más ambiciosos resultados de aprendizaje más que en formas más eficientes de alcanzar viejos objetivos (véase Jochems, Van Merriënboer y Koper, 2004). Existen experiencias en las que se utiliza la tecnología de forma creativa para diseñar nuevos objetivos y estrategias educativas, ensayando fórmulas prometedoras encaminadas a canalizar la fuerza potencial de los nuevos instrumentos tecnológicos. Pero esto no permite pensar que la tecnología por sí misma está conduciendo a una revolución en los procesos de enseñanza y aprendizaje.

\section{4.- La educación a distancia y el apoyo on line a la educación presencial}

Otro debate explora la pregunta: ¿Por qué es importante el e-learning? De nuevo la pregunta, ¿se trata de una mejora en el aprendizaje sin la "e”? Como comentábamos al comienzo, el carácter de la educación superior está cambiando. Los modernos sistemas de comunicaciones y el nacimiento de la World Wide Web han hecho necesario reconsiderar la "distancia" en la educación superior que se están convirtiendo en instituciones donde se matriculan cada vez más estudiantes ubicados en una variedad de lugares geográficos.

El uso de la educación a distancia o de las actividades on line en la educación superior ha crecido notablemente. Muchas universidades tradicionalmente presenciales utilizan materiales on line en los cursos para apoyar la enseñanza. En algunos casos los cursos son totalmente on line, mientras que otras proporcionan un apoyo complementario como material didáctico, actividades de aprendizaje o documentación (Ridchardson, 2000).

Este tipo de aprendizaje es a menudo descrito como "e-learning”, pero el "e-learning” se utiliza para describir una amplia gama de enfoques de aprendizaje apoyado en las TIC. Desde la década de los 60 la popular imagen de la revolución informática ha descansado sobre la instrucción individualizada asistida por ordenador y ahora que con el proceso de Bolonia se busca esto parece que este enfoque ha tomado de nuevo valor.

Un informe de la OCDE (2005) destacó cuatro tipos principales de e-learning: 1) webs complementarias al aula, donde los cursos son compatibles con los materiales en línea; 2) cursos que dependen de la web y que requieren de actividades en línea, como la colaboración en el trabajo o la evaluación de proyectos, de modo mixto, donde el aprendizaje en línea sustituye una proporción significativa de aprendizaje en el aula, pero donde la asistencia sigue siendo necesaria (también conocido como "blended learning"); 3) cursos totalmente on line donde la asistencia no es necesaria y los alumnos siguen un currículo on line. Aquí es importante hacer una distinción entre el uso de las TIC en la enseñanza tradicional de grupos de estudiantes en entornos tradicionales y los nuevos usos de las TIC para grupos de estudiantes no tradicionales.

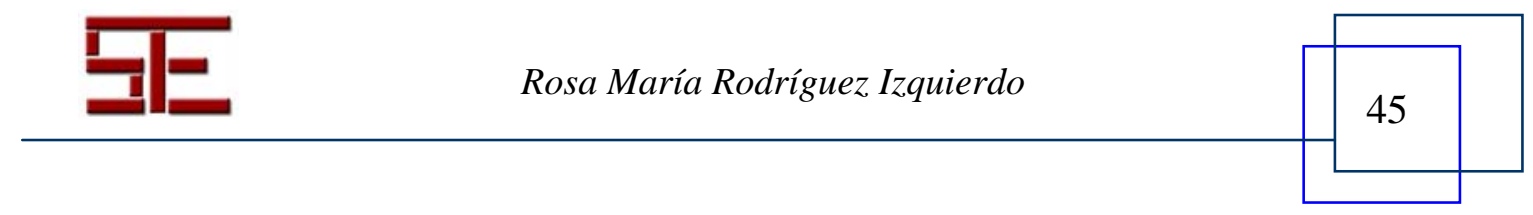




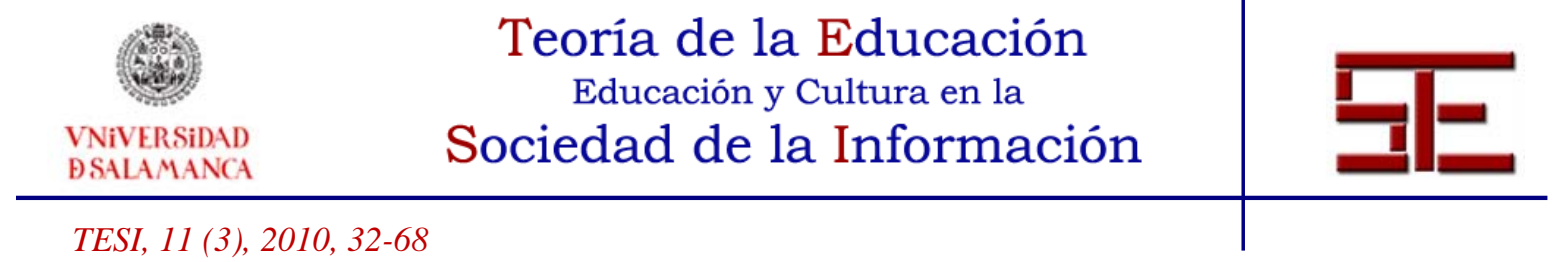

Las respuestas desde la literatura a las preguntas que nos hacíamos en este apartado son contradictorias debido a la amplitud de las concepciones de "e-learning”. Por una parte, hay autores que piensan que nos encontramos en una fase de "fijación técnica" donde se pone una fe infalible en el uso de la enseñanza on line en la educación superior. Esta postura se refleja en los miles de millones que se invierten anualmente en todo el mundo en diversos aspectos del uso de las TIC en la universidad. La mayor parte de esta financiación está dirigida a la aplicación en el campus de las tecnologías a distancia. Es más, los gastos de las universidades en infraestructuras han aumentado notablemente en la última década, como intento de las instituciones de "mezclar" las TIC en todos los aspectos de la enseñanza presencial para apoyar el estudio independiente de los estudiantes. Últimamente, el creciente uso de plataformas virtuales de aprendizaje como WebCT, Blackboard y Moodle ha visto ampliarse el concepto de campus universitario. Este tipo de tecnologías se han convertido en un icono en la educación superior del siglo XXI.

No obstante, la noción de los ciber-campus y del uso formal de las nuevas tecnologías sigue siendo desigual y muy variable de curso a curso y de una institución a otra (Breen et al., 2001; Marriott et al., 2004). Lo que la literatura apoya es que el uso potencial de las poderosas tecnologías de la información en las aulas se ve que, con frecuencia, adopta la forma reducida de actividades sin sentido que contribuyen a alterar poco las expectativas y las prácticas de enseñanza superior (Moule, 2003). Parece evidente que es necesario cambiar el modelo educativo actual y evolucionar hacia otro donde se atienda adecuadamente a la demanda existente pero con calidad. Las TIC contribuyen a conformar tales entornos de aprendizaje pero generalmente no son suficientes, como ponen de manifiesto Sangrá y Gonzáles (2004), al menos en el estado de desarrollo tecnológico actual. De hecho, el uso formal de las tecnologías en muchos ámbitos de la educación superior podría ser descrito como esporádico, desigual y, a menudo, "de bajo nivel". En marcado contraste con el uso imaginativo e informal que hacen los estudiantes y los profesores de tecnologías como la telefonía móvil y otros dispositivos digitales personales. Esta situación ha llevado a algunos a calificar las TIC en la educación superior como nada más que un "área de servicio" del currículo y algo con lo que muchos estudiantes y profesores se muestran reacios a comprometerse de manera activa o sostenida (Reffell \& Whitworth, 2002). Westbrook $(2006,480)$ llega a la conclusión de que para que "los cursos en línea sean efectivos tienen que darse una formación y un apoyo adecuado tanto para los profesores como para los alumnos mientras desarrollan nuevas estrategias en respuesta a las nuevas tecnologías para el aprendizaje".

Por otra parte, existen investigaciones que subrayan que el uso de las TIC de manera eficaz permite a los estudiantes lidiar con problemas del mundo real, el acceso adecuado a información rápida y fácil, compartir sus ideas con sus compañeros, lo que facilita el trabajo en grupo, y construir nuevos conocimientos y significados por sí mismos en un

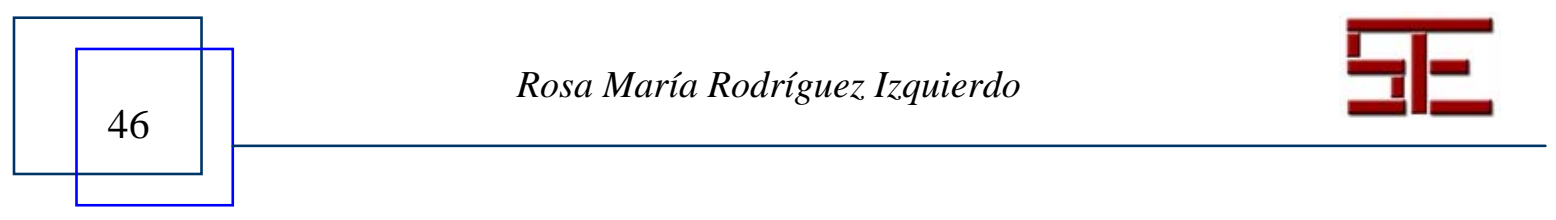




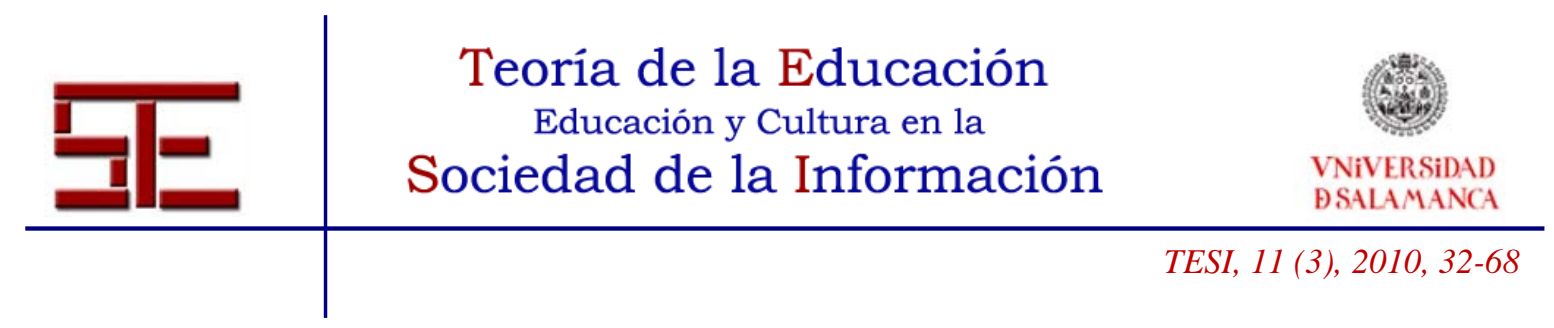

contexto relevante e interesante. Como $\operatorname{Kozma}(1994,8)$ ha argumentado, el aprendizaje es "una interacción entre los procesos cognitivos y las características del medio ambiente". En un entorno de aprendizaje constructivista, la tecnología puede proporcionar representaciones y modelos de operaciones en una forma que los alumnos no pueden proporcionar por sí solos. Los entornos virtuales de aprendizaje son particularmente valiosos para la visualización y la representación de la información visual compleja (Hedberg, 2006). En la página web de la Universidad de Leicester (2005) se afirma que el elearning ofrece "un entorno de trabajo muy visual" que "puede mantener el interés y aumentar la motivación en los alumnos" y donde éstos pueden ser apoyados con mayor flexibilidad, pueden localizar, recuperar, interactuar con los recursos educativos y colaborar con profesores y compañeros de estudios en formas que antes no eran posibles”. Más adelante haremos referencia a las comunidades virtuales de aprendizaje.

Según los estudios de Candy (1998) este tipo de software ofrece textos o multimedia de instrucción, haciendo que los estudiantes se hagan preguntas y proporcionándoles información y nuevos materiales didácticos sobre la base de la respuesta del estudiante. Cada estudiante trabaja con estos materiales de manera diferente y a un ritmo distinto. Esto requiere la comprensión de cómo aprenden los estudiantes y de cómo aprenden en estos entornos que se desarrollan para ellos (Byrne et al., 2002; Price y Richardson, 2003). Esta cuestión es particularmente pertinente si queremos hacer frente a las cuestiones relativas a la mejora de la calidad del aprendizaje de los estudiantes como oposición a jugar el juego de cumplir con las metas institucionales de virtualizar la enseñanza.

Para Butler y Winnie (1995) una de las posibilidades de la incorporación de Internet en los procesos educativos es que proporciona la oportunidad del aprendizaje autorregulado, mediante el cual se genera en los alumnos un estilo propio de implicación en la resolución de tareas, estableciendo sus propias metas, planteando sus propias estrategias para evaluar el grado de cumplimiento de los objetivos, procesando información y encontrando recursos para aprender

Otros investigadores como, por ejemplo, Draper y Brown (2004), Corlett et al. (2005) y Oliver (2006) defienden la capacidad de las TIC para activar en los estudiantes la capacidad para aprender, así como para mejorar y democratizar el acceso a las oportunidades educativas y apoyar la interactividad, la interacción y la colaboración entre los alumnos.

Entre las muchas expectativas en relación con el creciente uso de las TIC en la enseñanza universitaria nos encontramos con que va a conducir a una mayor diversificación en las instituciones de educación superior, con la inclusión de nuevos grupos de estudiantes y una creciente movilidad internacional, tanto real como virtual, de los estudiantes tra-

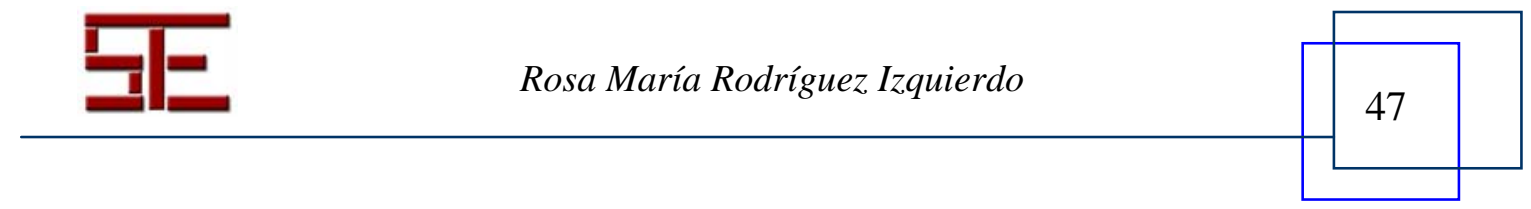




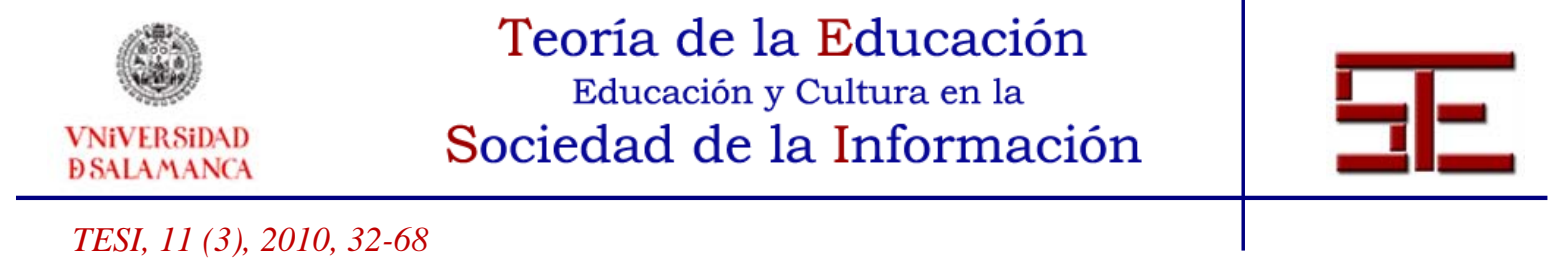

dicionales y de los no tradicionales. Como consecuencia, para autores como Eriksen (2001), la principal cuestión en estos días no parece ser si las universidades deben adoptar la educación a distancia en sus programas de estudio para tratar de permanecer en esta competición, ni las muchas consecuencias que esto podría tener para la educación superior, sino la rapidez con que pueden poner en práctica las oportunidades que las TIC ofrecen.

Este sentimiento de urgencia relacionado con la necesidad de utilizar las TIC y con su actualización continua en la educación universitaria ha llevado a muchas universidades a adaptar un enfoque más orientado a la acción (Schmidtlein \& Taylor, 2000) y al producto final que a los procesos detrás de un buen funcionamiento de la incorporación de las TIC en la enseñanza y el aprendizaje (Pedro, 2001).

Las respuestas a esta exigencia son variadas. El Massachusetts Institute of Technology (MIT) ha realizado un gran número de cursos disponibles gratuitamente en la web (MIT, 2006), mientras que otras universidades ofrecen algunos cursos en asociación con organizaciones internacionales asociadas. Asimismo, en los últimos años se han establecido una serie de consorcios mundiales de universidades para ofrecer cursos on line transnacionales, por ejemplo, la Global University Allianca and Universitas 21. Muchas universidades en los países occidentales están adoptando un enfoque de aprendizaje mixto, es decir, una fusión del aprendizaje presencial y mediado por la tecnología de aprendizaje.

La literatura sugiere que los programas de un ordenador portátil por estudiante pueden dar lugar a la integración de la tecnología en el plan de estudios y a ayudar a satisfacer la necesidad de la tecnología de los estudiantes (Hall \& Elliott, 2003; Lowther, Ross \& Morrison, 2003; McVay et al., 2005). Sin embargo, por la experiencia se aprende rápidamente que el acceso a los ordenadores portátiles no es suficiente para apoyar y transformar la pedagogía. El éxito de la aplicación depende más bien de otros cambios que deben producirse para que afecten a los procesos y a los métodos de enseñanza (Cradler et al., 2002). Es en la relación entre el propósito, las personas y la pedagogía donde se puede ganar mucho. Como Oliver y Dempster (2003) manifiestan las TIC no necesariamente cambian la pedagogía, como tal, pero deben ir acompañadas de medidas que estimulen y alienten este cambio.

En resumen, el giro hacia la enseñanza y el aprendizaje apoyado en las TIC ha despertado un gran interés en los últimos 30 años y ha revitalizado el sector universitario. Por lo tanto, crudos ultimátums siguen siendo manifestados por los tecnólogos de la educación en los que las universidades deben "transformarse o morir" de cara al progreso tecnológico (Bates, 2004). Por otro lado, es poco probable que se mejore la enseñanza y el aprendizaje en la educación superior simplemente por la aplicación de una nueva tecno-

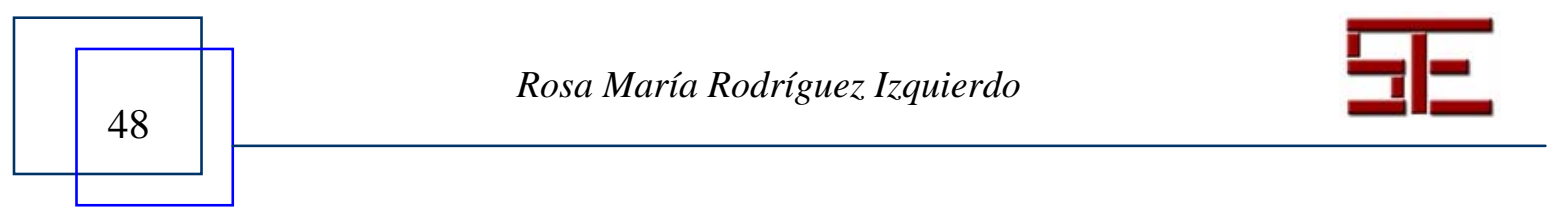




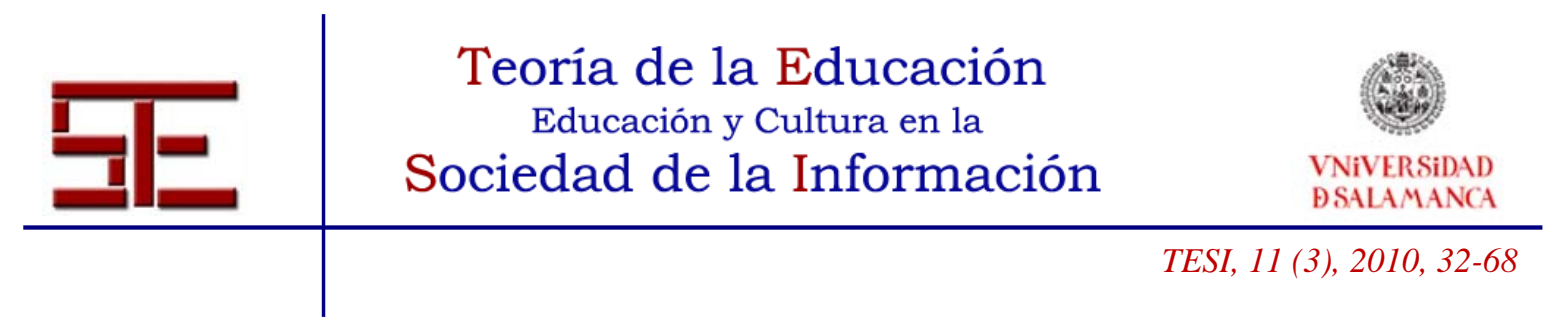

logía. Sin embargo, el aprendizaje se puede mejorar cuando la utilización de las TIC tiene en cuenta no sólo las características de la tecnología sino también el diseño pedagógico, el contexto en el que el aprendizaje tiene lugar, las características del estudiante y su experiencia previa y familiaridad con las tecnologías involucradas (Phipps \& Merisotis, 1999). Así que, si bien las TIC pueden permitir que tengan lugar nuevas formas de enseñanza y aprendizaje, no pueden garantizar la eficacia y la adecuación de los resultados del aprendizaje que se logren. No se trata de tecnologías, sino de los propósitos educativos, que deben proporcionar el liderazgo. Los estudiantes tienen que comprender no sólo la manera de trabajar con las TIC, sino ¿cuál puede ser el beneficio para hacerlo?

\section{5.- Comunidades de aprendizaje}

Según las investigaciones de Sherman y Kurshan (2005) las plataformas de aprendizaje como Blackboard, TopClass, y WebCT, etc., alientan el "constructivismo" y el aprendizaje centrado en el alumno. Este software construye "comunidades virtuales" mediante la gestión de la comunicación en línea entre participantes, a veces distantes, en un espacio asincrónico.

Aunque los más antiguos sistemas aparecieron en la década de 1980, las principales plataformas de aprendizaje on line se han desarrollado en los últimos veinte años, este enfoque de aprendizaje no está aún maduro en relación a la interactividad aunque los educadores han desarrollado habilidades y estrategias para el aprendizaje en línea que pueden hacer estos medios sofisticados (véase, por ejemplo, Salmón, 2002). Al menos supuestamente, este tipo de herramientas facilitan el aprovechamiento de las posibilidades de inmediatez, ubicuidad y universalidad que es posible con Internet a la vez que permiten interacciones antes inimaginables. Las TIC contribuyen a conformar tales entornos de aprendizaje, pero, generalmente, las TIC no son suficientes, al menos en el estado de desarrollo tecnológico actual.

La construcción de tales comunidades no es tarea sencilla. La literatura sugiere que son necesarios algunos elementos tales como: 1) El primer elemento consiste en la búsqueda de nuevas ideas, habilidades, materiales para la interpretación de su significado. 2) El segundo elemento hace hincapié en la importancia de la dimensión social del aprendizaje. Schlager y Fusco (2003) sugieren que aprendemos mejor cuando se trabaja con una tecnología que permita el diálogo y la acción comunitaria. 3) El tercer elemento reconoce que el aprendizaje debe estar estrechamente vinculado a la situación de los alumnos. Los estudiantes necesitan ser capaces de aplicar, experimentar y reflexionar sobre las nuevas ideas y enfoques en situaciones reales. 4) El cuarto elemento es que se necesita tiempo para desarrollar una comunidad social donde las razones para el cambio de las creencias y de los conceptos puedan ser exploradas completa y abiertamente.

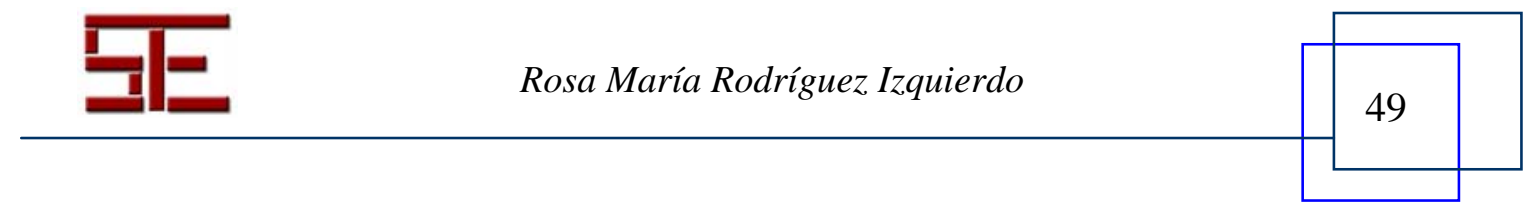




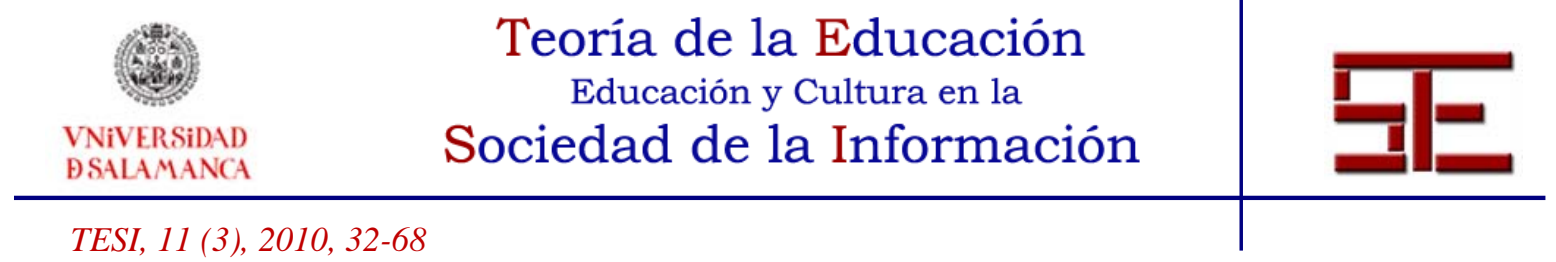

Según los hallazgos de Laird y Kuh (2005, 231), si se dan estos elementos estas tecnologías pueden llegar a constituir una nueva forma de compromiso entre estudiantes y profesores y "puede haber áreas, donde la interacción alumno-docente a través del uso de la tecnología constituya una forma diferente o adicional de interacción que hace su propio aporte a la enseñanza y el aprendizaje independientemente de los demás tipos de contacto entre estudiantes y profesores".

Benson y Harkavy (2002) argumentan que la capacidad de crear comunidades de aprendizaje virtuales podría ofrecer una oportunidad para reinventar radicalmente y "salvar el alma de la universidad" a la luz de la evolución del contexto mundial de la educación. En otras palabras, se considera por un número creciente de investigadores críticos que las TIC tienen el potencial de ser usadas para una actualización epistemológica y cultural y para el reposicionamiento de la universidad, lejos del modelo instrumental y homogeneizador de la universidad empresarial y hacia un modelo "global y cosmopolita" de la tecnología basada en la educación superior. Por lo tanto, muchos autores han estado explorando las maneras en que las universidades pueden utilizar viejas y nuevas tecnologías para "reinventarse como lugares de encuentro de las culturas y saberes de todo el mundo” (Robins \& Webster, 2002, 322).

La popularidad de sitios web como facebook.com demuestran la fascinación de espacios que permiten el desplazamiento de información y la capacidad para establecer conexiones entre personas y contenidos. Estos sitios ofrecen la oportunidad de enviar vídeos, imágenes y textos, para vincular contenidos y crear redes sociales con gente de intereses similares. Un desarrollo que puede proporcionar modelos para el futuro con iniciativas de aprendizaje más ampliamente disponibles. Éstos incluyen las iniciativas de contenido abierto de los EE.UU. como las del MIT (2006) y la Open University del Reino Unido (2006). En cambio, la Alliance for Lifelong Learning (Alianza para el aprendizaje permanente) (2006) a través de Oxford, Stanford y Yale, se derrumbó en 2006. Por lo tanto, es importante entender más acerca de cómo y por qué estas aulas mixtas y basadas en enfoques de aprendizaje con el apoyo de Internet funcionan para evitar experiencias poco exitosas en el futuro.

\section{6.- Los cambios en los roles del profesorado}

Las TIC deberían incorporar un cambio en la forma de organizar la enseñanza y el aprendizaje. De acuerdo con Martínez Martín (2008, 228):

Conviene que tal integración comporte un auténtico cambio en el profesorado tanto en la manera de comprender tales procesos como en la de disponer los contenidos de aprendizaje, de forma que la integración de tecnologías no sea un simple cambio de escenario en el espacio de aprendizaje universitario -menos presencial, más virtual y más

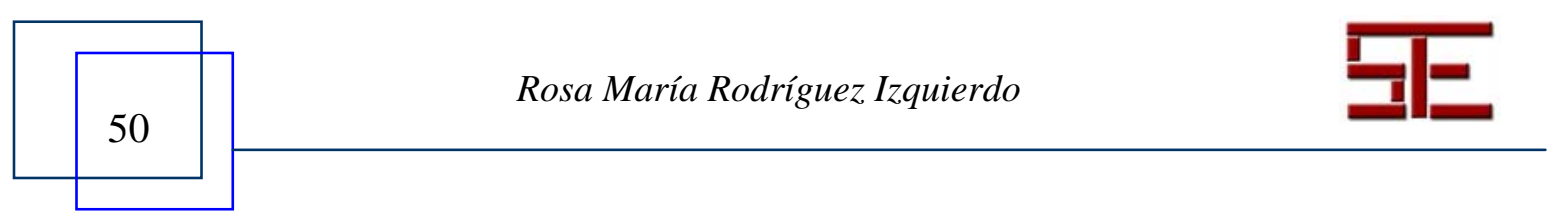




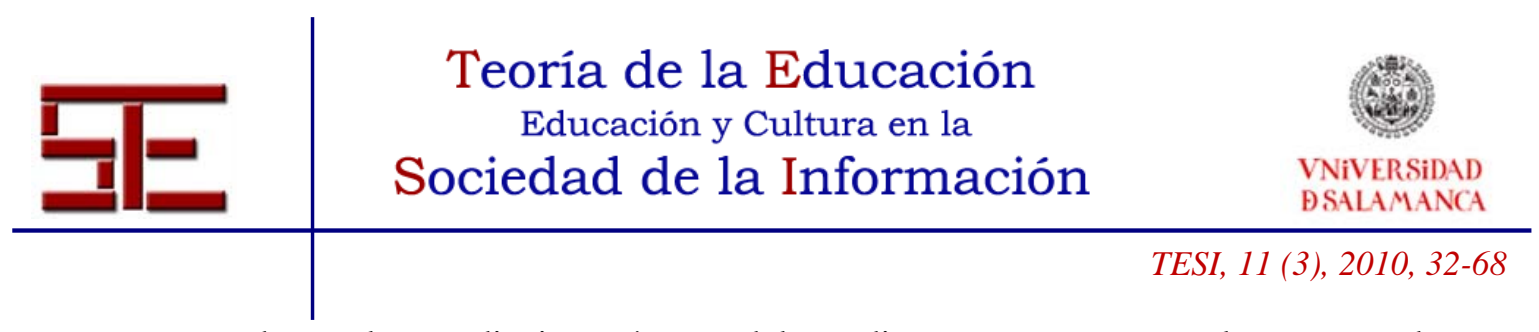

centrado en el aprendizaje autónomo del estudiante- y comporte realmente una docencia más eficiente y más aprendizaje en el estudiante y de mayor calidad.

Y ello requiere que el profesor esté más centrado en el aprendizaje que en la enseñanza y por ello es necesario cuidar la organización y disposición de los contenidos de aprendizaje, así como de la organización del aprendizaje de los alumnos mediante tareas individuales y en grupo, con un seguimiento cuidado y permanente por parte del profesor (McManus, 1998). En estos entornos, el profesorado debe estar siempre al alcance. Su función no es sólo enseñar o transmitir conocimiento sino que, principalmente, asesora y guía al estudiante en una materia concreta o asignatura durante todo el proceso de aprendizaje. Es quien propone al estudiante cómo abordar los contenidos de la materia, los grandes ejes temáticos que la configuran y las cuestiones fundamentales de los materiales didácticos en su conjunto. Sugiere ritmos y estilos concretos de estudio, planifica con el estudiante, formula criterios de evaluación y evalúa el proceso seguido por el alumno, aclara sus dudas, resuelve sus dificultades de comprensión y, en definitiva, les ayuda a superar con éxito los aprendizajes. En este enfoque, la planificación juega un papel fundamental como demuestran en nuestro contexto trabajos como los de Bates (2004) y Colas y De Pablos (2005). Por lo tanto, convenimos con Paredes y Estebanell (2005) que conviene apoyar este proceso en la transformación de las actitudes del profesorado.

Se está demandando por tanto un profesor entendido como "trabajador del conocimiento”, diseñador de ambientes de aprendizaje, con capacidad para rentabilizar los diferentes espacios en donde se produce el conocimiento (Cranston, 1998). Los profesores, en lugar de impartir los conocimientos en las aulas, se transforman en orientadores y mediadores de la actividad educativa (Salinas, 1998), trabajan en equipo en la producción de materiales que vehiculen y sirvan de soporte a los conocimientos.

Para conseguir este propósito, el profesorado deberá ser preparado para capitalizar al máximo los beneficios que le posibilitan las tecnologías en cuanto que: favorecen escenarios de aprendizaje distintos, centrados en el alumnado, brindándole diversas modalidades de interacción, aportándole diversos contextos y modos de seguimiento de su propio proceso de aprendizaje, partiendo de sus intereses personales, suscitando actividades de aprendizaje colaborativo, desarrollando una mayor autonomía de trabajo y aprendizaje autorregulado, rompiendo con situaciones de aprendizaje pasivo y acumulativo y dependiente del profesor que realizaba el alumno (Area, 2005).

Sin embargo, la investigación indica que el profesorado se siente a la vez amenazado por el cambio y, en cambio, no impresionado por el cambio que parece centrarse en lo que la tecnología puede hacer más por el aprendizaje. El cambio de las funciones que se

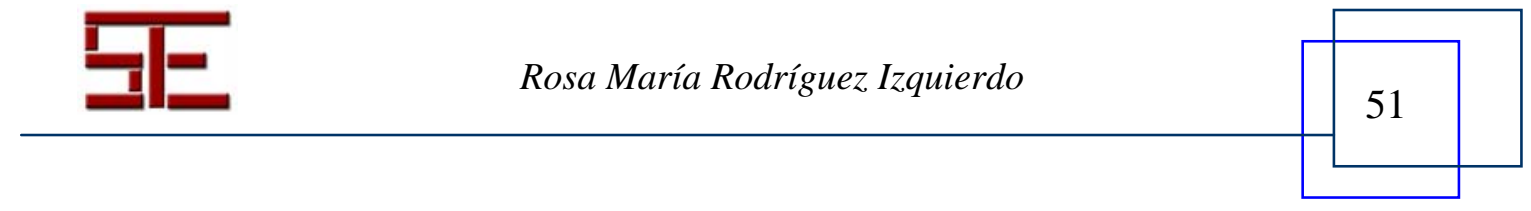




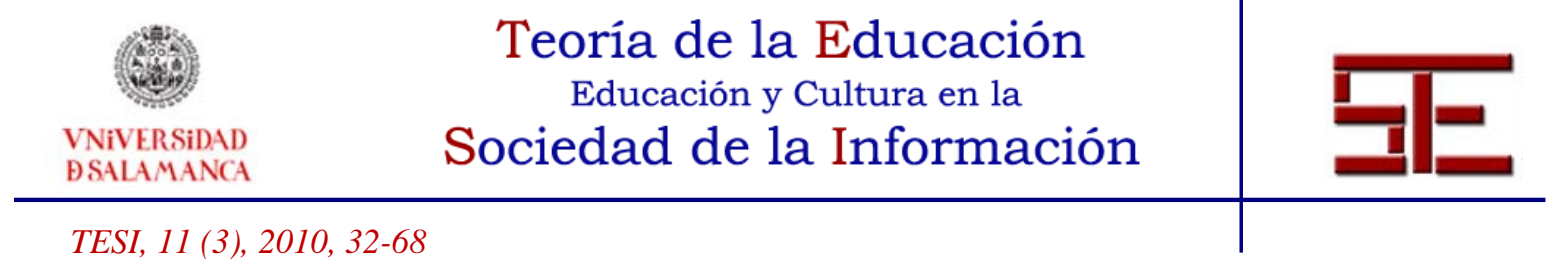

requieren en el profesorado es, a menudo, percibido como la creación de trabajo adicional e innecesario. Como Owen y Demb (2004, 662-663) describen:

El profesorado se siente frustrado por la cantidad de tiempo necesario para el adecuado desarrollo y mantenimiento potenciado por la tecnología o los cursos en línea, así como con el tiempo invertido en la atención a las necesidades de aprendizaje de los estudiantes. La frustración se deriva no sólo del número de nuevas actividades, sino también del hecho de que sus esfuerzos de trabajo no son tenidos en cuenta en los antiguos modelos, cuya estructura no se ajustaba a este nuevo trabajo, por lo tanto, no proporcionan la base adecuada para el reconocimiento y la recompensa.

Finley y Hartman (2004, 328-329) han observado que: “...los profesores experimentan con la integración de la tecnología si creen que es coherente con su estilo de enseñanza, si sienten que están bien cualificados y se creen competentes, si son apoyados y recompensados por hacerlo, y si pueden ver que es pedagógicamente útil”. Esta observación contiene una serie de pistas para lograr el cambio tecnológico en un ambiente académico y la puesta en marcha de buenas prácticas.

\section{7.- Las resistencias de los estudiantes}

Selwyn (2003, 2007) y Selwyn, Marriott, Marriott, (2000) y Duart y Lupiáñez (2005) han escrito también persuasivamente acerca de las maneras en que podemos interpretar razonablemente la reticencia de los estudiantes universitarios a comprometerse con las TIC en sus estudios. Estos autores conceden poca atención al déficit de teorías que tratan de localizar las raíces del problema en la falta de competencias o en la tecnofobia de los estudiantes. Por el contrario, ellos ven que los estudiantes hacen opciones activas, informadas por las señales más o menos evidentes que reciben por parte de los profesores sobre el currículo, los sistemas de evaluación y las demandas de trabajo y lecturas que tengan que realizar. Si los alumnos ven que el éxito de su curso no se va a ver afectado positivamente por el uso de la tecnología no abandonan sus esquemas para utilizarlas.

Los estudiantes pueden ver cómo las tecnologías desempeñan un papel vital en su futuro lugar de trabajo pero esto por sí solo no será suficiente para motivarlos a utilizarlas en sus estudios, especialmente si consideran que los empresarios en el momento de la selección van a dar mayor prioridad a otras habilidades y conocimientos, y que les proporcionarán la formación adecuada en el lugar de trabajo en cuanto a las habilidades específicas requeridas por la tecnología (Selwyn, 2003; Selwyn et al., 2000).

Estas ideas están en consonancia con los últimos datos de la encuesta de estudiantes del Reino Unido y Australia, que ponen de manifiesto algunas de las predilecciones de la generación de estudiantes en el uso de las tecnologías. Un estudio británico reciente

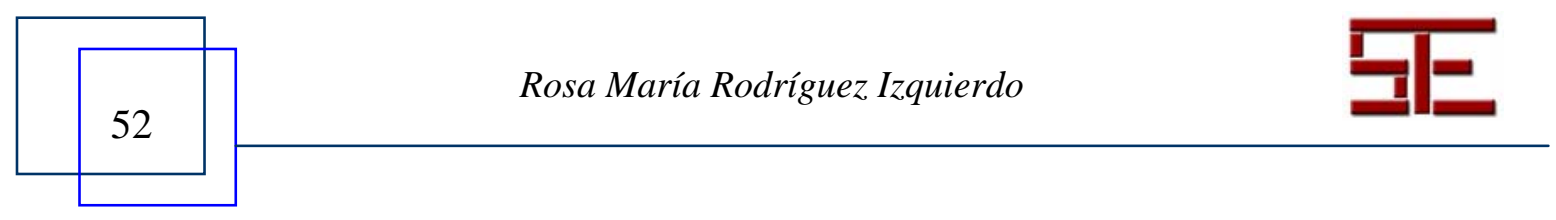




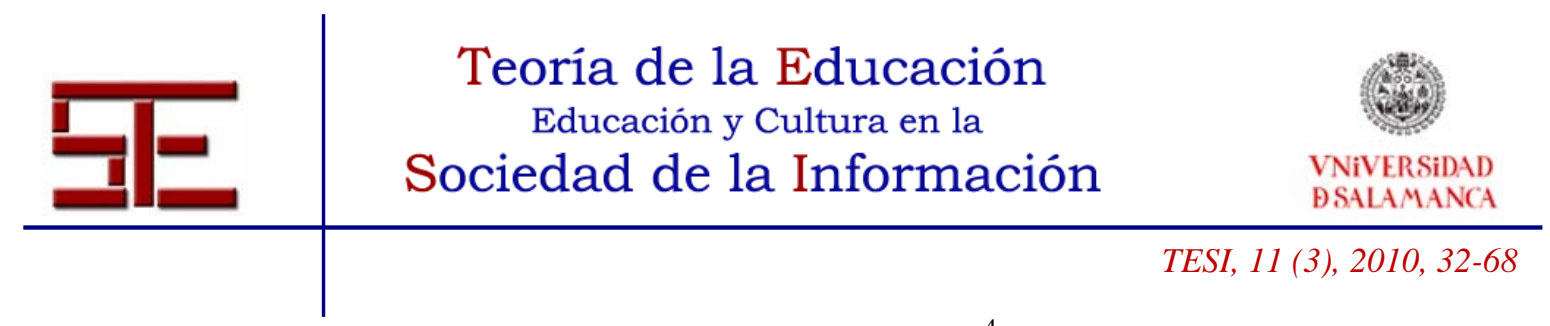

realizado por el Joint Information Systems Committee ${ }^{4}$ (2007) revela que los nuevos estudiantes universitarios están inseguros de cómo va a ser el uso de la tecnología en su educación y buscan la orientación de los profesores acerca de cómo hacer un uso adecuado de las tecnologías educativas. Estos estudiantes conocen cómo usar las TIC y los medios digitales pero no quieren sustituir el encuentro cara a cara en la enseñanza y la interacción social.

Del mismo modo, Barnes, Marate y Ferris (2007) han afirmado que los blogs han sido durante mucho tiempo un elemento básico para la actividad en la generación de estudiantes. Sin embargo, los últimos datos de la encuesta de Australia (2.588 estudiantes universitarios que se encontraban en su primer año en 2006) mostraron que el $73 \%$ de los estudiantes nunca habían escrito en un blog y el 55\% de los estudiantes nunca habían leído uno (Kennedy et al., 2007).

Conacannon et al. $(2005,511)$ indican que "los estudiantes ven el aprendizaje electrónico como una parte esperada e integral del proceso de aprendizaje en la educación superior". El principal hallazgo en un estudio sobre la percepción de los estudiantes en relación al e-learning en la educación universitaria es "que la estrategia de aplicación del elearning juega un papel crucial para los estudiantes en la percepción de la nueva tecnología" (Keller \& Cernerud, 2002, 66).

En resumen, es peligroso hacer suposiciones acerca de la adopción o el rechazo de la tecnología educativa de los estudiantes universitarios. Sus opciones y prácticas están definidas de forma muy sutil.

\section{8.- Tecnologías emergentes y nuevos espacios de aprendizaje}

En esta sección se revisan los vínculos entre la evolución de la pedagogía y las tecnologías emergentes. El objetivo es favorecer el pensamiento en la versatilidad de la enseñanza y el aprendizaje. ¿Qué aportan las tecnologías móviles (m-tecnologías) con respecto a las estrategias de e-learning (m-learning)? El tema con estas tecnologías emergentes es que permitirán que más contenidos estén disponibles.

Armastas et al. (2005, 27) sostienen que "las tecnologías móviles no pueden ser ignoradas como parte de la combinación del e-learning". El m-learning (aprendizaje electrónico móvil) "es el arte apasionante de la utilización de tecnologías móviles para mejorar la experiencia de aprendizaje. Los teléfonos móviles, PDA, Pocket PC e Internet pueden ser usados para comprometer y motivar a los alumnos, en cualquier momento y en cualquier lugar". Geddes (2004) señala cuatro grandes ventajas del m-learning: el acceso, el contexto, la colaboración y el atractivo.

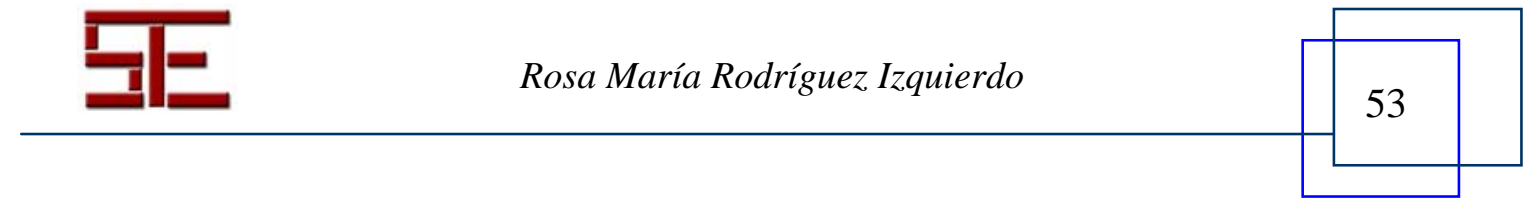




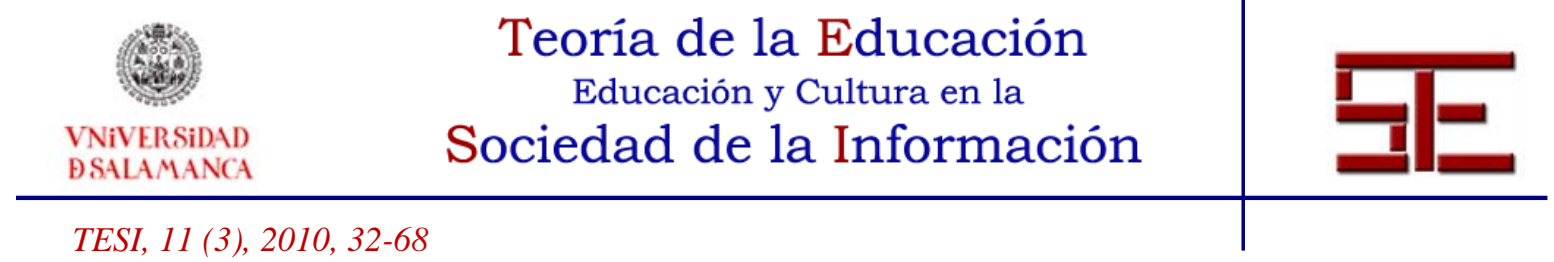

Armastas et al. $(2005,29)$ y Attewell (2005, 13-14) han tratado también de identificar los beneficios educativos y las diversas posibilidades de las tecnologías móviles en la educación superior. Estos beneficios incluyen el uso de tecnologías móviles para la entrega de materiales y tareas multimedia interactivas, la posibilidad de la colaboración independiente y de crear experiencias de aprendizaje, el incentivo para que los estudiantes participen activamente en conferencias y para ayudar a los estudiantes a permanecer más centrados durante más tiempo. Las tecnologías móviles como el GPS, los teléfonos móviles y las PDA también permitirán a los estudiantes conectarse con los investigadores de sus áreas de conocimiento y pueden hacer más accesible la información.

La evolución de la tecnología móvil sugiere que los recursos pueden ser entregados a los alumnos en cualquier lugar y en cualquier momento (Anderson \& Blackwood, 2004). Como resultado de ello ya hay cambios en los principios de diseño de los nuevos espacios de aprendizaje. Por ejemplo, Alexander (2006) ha sostenido que los educadores anteriormente estaban preocupados por diseñar las bibliotecas como espacios de aprendizaje, en el futuro, tienen que diseñar el aprendizaje para cualquier espacio. Estos enfoques no son contradictorios sino que requieren un punto de partida diferente. Alexander ha sugerido que la capacidad de poner los recursos de aprendizaje al alcance de los alumnos a través de la tecnología móvil va a resultar una revolución para todos los alumnos. Si Alexander lleva razón, entonces" la versatilidad del profesorado puede tener que aumentar para proporcionar más recursos de aprendizaje portátil. Es posible que tengamos que trabajar con proveedores de tecnología móvil, proveedores de recursos de aprendizaje, bibliotecas y tecnólogos del aprendizaje”.

El Podcasting ${ }^{5}$ es un excelente ejemplo de una tecnología emergente que puede aumentar nuestra versatilidad pedagógica. Los podcasts proporcionan servicios de correo electrónico y un blog para que cualquier oyente pueda contactar y responder las preguntas. Mucho se ha escrito sobre el potencial de los podcasts pero todavía no suficiente de cómo los alumnos pueden participar con ellos y sobre cómo influyen en su aprendizaje. Un ejemplo es el de Chan y Lee (2005) en el que aportan pruebas de cómo cinco minutos de programas de audio centrado en el estudiante pueden abordar los prejuicios y ansiedades sobre temas y actividades de aprendizaje. Este ejemplo aislado debe ser asociado con la realización en el 2007 del IMPALA (Informal Mobile Podcasting And Learning Adaptation) una importante institución de estudio transversal sobre el podcasting en la enseñanza superior dirigido por la Universidad de Leicester y financiado por la Academia de Educación Superior.

Existe cierta investigación para orientar la evaluación y los métodos de ejecución pero es aún insuficiente. Baldwin-Evans (2006, 157-163) identifica varios pasos en la aplicación de nuevas estrategias de aprendizaje. Las medidas incluyen: garantizar la disposición de los alumnos (incluir sesiones de orientación), ganar la atención de los alumnos

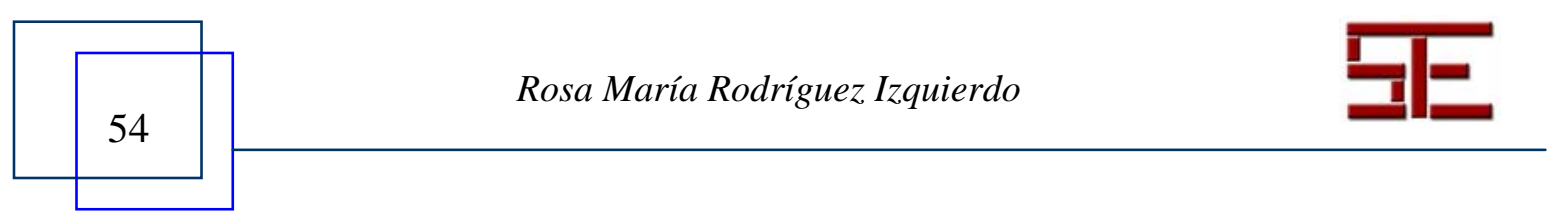




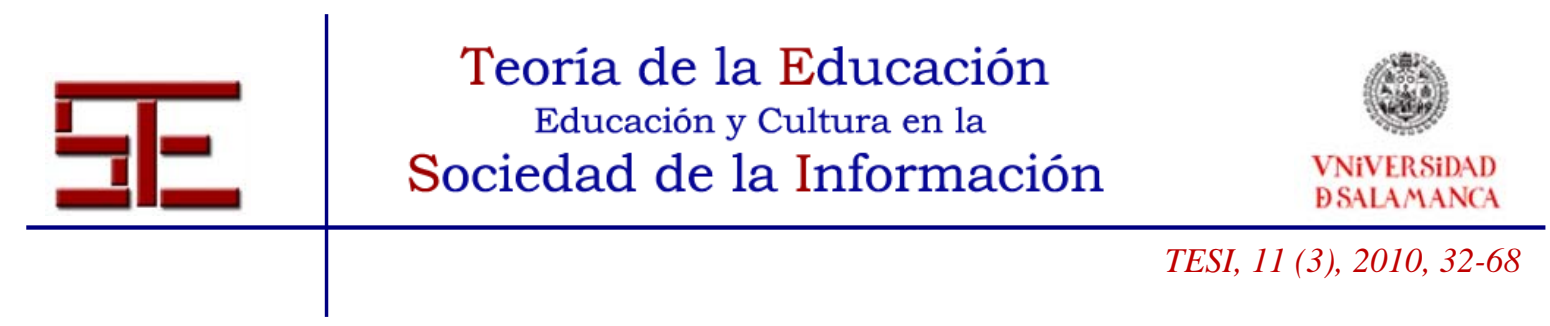

(incluir un resumen de los objetivos de aprendizaje y la estimulación del aprendizaje previo), dando a los estudiantes oportunidades de aprendizaje experimental; ofreciendo a los estudiantes oportunidades para experimentar y consolidar el aprendizaje (estudios de casos, juegos de rol, simulaciones, autoevaluación); garantizar una buena evaluación de los mecanismos de retroalimentación a los estudiantes, proporcionando apoyo y asistencia para ampliar el aprendizaje (preguntas frecuentes, mentores o coaching por pares) y permitir oportunidades para la colaboración con otros.

Por otra parte, como ponen de manifiesto algunos trabajos en nuestro contexto (Sevillano, 2005; Cebrián, 2003; García-Valcárcel, 2003; Salinas, 2004; Duart y Lupiáñez, 2005) tanto el alumnado como el profesorado deben adquirir el conocimiento sobre cómo trabajar a través de estos nuevos recursos, cuestión que no siempre es contemplada convenientemente.

Si bien la disponibilidad y el uso de tecnologías de m-learning se encuentran en un momento de desarrollo evidente, las perspectivas críticas sobre el uso de estas tecnologías desde la práctica no han sido aún tenidas en cuenta. Esto no significa que estas TIC no son valiosas, sino más bien que su uso no es reflexivo aún. De nuevo, el uso es impulsado por la tecnología más que por razones pedagógicas. Sin embargo hay pruebas de que los beneficios educativos son reales y deberán ser explorados.

\section{1.- A MODO DE CONCLUSIÓN}

La incorporación de las TIC significa novedad y adaptación a los tiempos. Las universidades informatizadas se cotizan bien en el mercado pero los resultados concretos en la utilización de las TIC en la enseñanza y en el aprendizaje son todavía escasos. El punto más importante a la conclusión de los estudios presentados en este artículo es que la tecnología es pieza clave en la sociedad actual pero no es la solución mágica a los problemas educativos. Las TIC no pueden cambiar por sí mismas el aprendizaje ni la enseñanza. No hay magia que valga. Las tecnologías serán lo que les permita ser el paradigma dentro del cual estén operando. Ya sabemos lo que las tecnologías dan de sí cuando siguen un paradigma reproductivo. Pueden potenciar, magnificar o facilitar el efecto de la acción humana, pero no su dirección, ni su sentido. Las TIC por sí mismas no cambian los procesos de enseñanza y aprendizaje, aunque puedan aumentar casi ilimitadamente sus efectos.

La literatura parece apuntar que la simple incorporación de las TIC a la enseñanza universitaria no garantiza la efectividad en los resultados alcanzados, como no lo hizo en su momento la introducción de los libros de texto o los audiovisuales. De igual forma que en otros ámbitos sociales, las TIC presentan una posibilidad importante en la redefinición de la práctica pedagógica en la educación superior. Pero igual que tienen potencia-

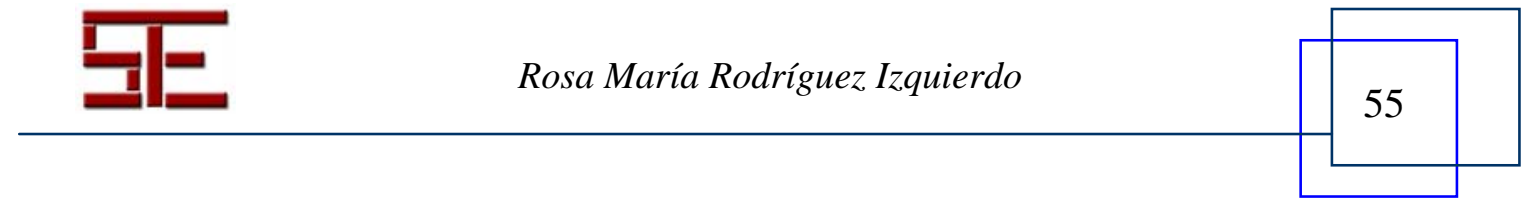




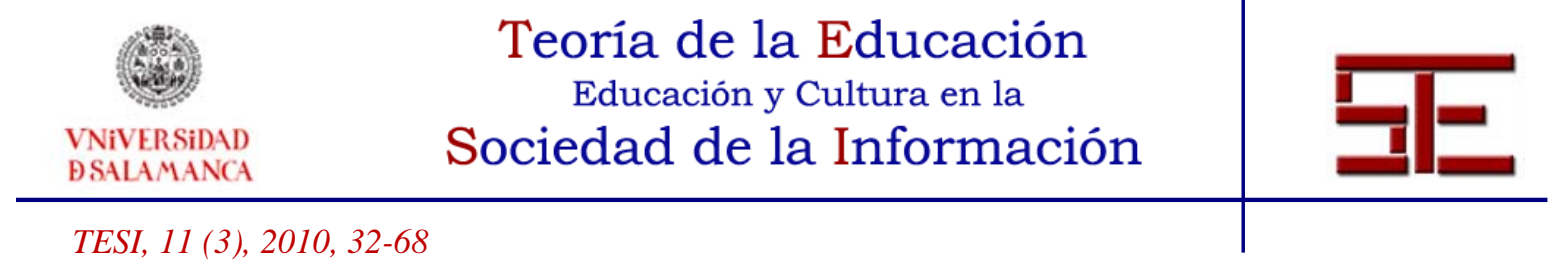

lidades pedagógicas más o menos evidentes y trabajadas también implican unos retos muy concretos a superar. Por tanto, quizás lo más importante es saber a dónde vamos y no el medio que utilizamos.

Como ha observado Kerr (2005, 1009-1010), la historia social de la tecnología sugiere que no siempre sabemos para lo que la tecnología es "buena" en cualquier momento o en cualquier institución. No toda la aplicación tecnológica da iguales resultados en diferentes contextos. El éxito depende tanto de la selección prudente de recursos tecnológicos como de los modelos y metodologías con que se emplean para reformar la tarea educativa. El uso de las TIC en el nuevo modelo de aprendizaje requiere de una redefinición de las funciones de los elementos que forman el sistema, de lo contrario no sólo no se evolucionará en la dirección adecuada sino que tendría efectos contraproducentes. No se puede ignorar que Estados Unidos, el país más “desarrollado” del mundo en las tecnologías de la información y de la comunicación, el multimedia, el Internet, etc., tiene un nivel de instrucción especialmente deplorable según un estudio de la Organización de Cooperación y Desarrollo Económico (OCDE, 2005).

El reto que tenemos por delante es repensar cómo se produce la integración de las tecnologías en los procesos de enseñanza y aprendizaje. Es preciso que la integración comporte un auténtico replanteamiento de todos los elementos del proceso de forma que la integración de las TIC conlleve una docencia más eficiente y aprendizajes de mayor calidad en los estudiantes.

Aunque los resultados de la investigación no son concluyentes, lo que parece claro es que la inclusión de estas nuevas herramientas en los procesos de enseñanza y aprendizaje va más allá del mero uso de las tecnologías (Cuban, 2008) y traerá consigo cambios en el proceso de enseñanza-aprendizaje, en la actuación del profesorado, en los métodos de enseñanza, etc. La introducción de las TIC conlleva dos implicaciones:

1. La cantidad de funciones que cambian el contenido de las tareas del profesorado a una combinación de elaboración de contenidos como expertos en proceso de aprendizaje y en el proceso gestor de la aplicación, y

2. La tecnología, a veces, no será tan importante como una serie de cuestiones tales como las tareas de aprendizaje, las características del alumnado, la motivación del estudiante y del profesorado.

Sostenemos que es esencial desarrollar una mejor comprensión de las cuestiones relacionadas con el uso de las TIC, de modo que las innovaciones no sean absorbidas por la tecnología sino que estén orientadas por la pedagogía. Las nuevas circunstancias del aprendizaje y del alumnado exigen que se tengan en cuenta no sólo las características de

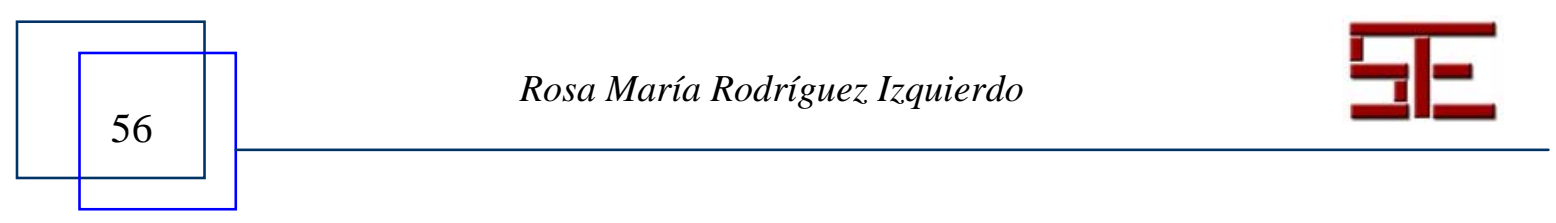




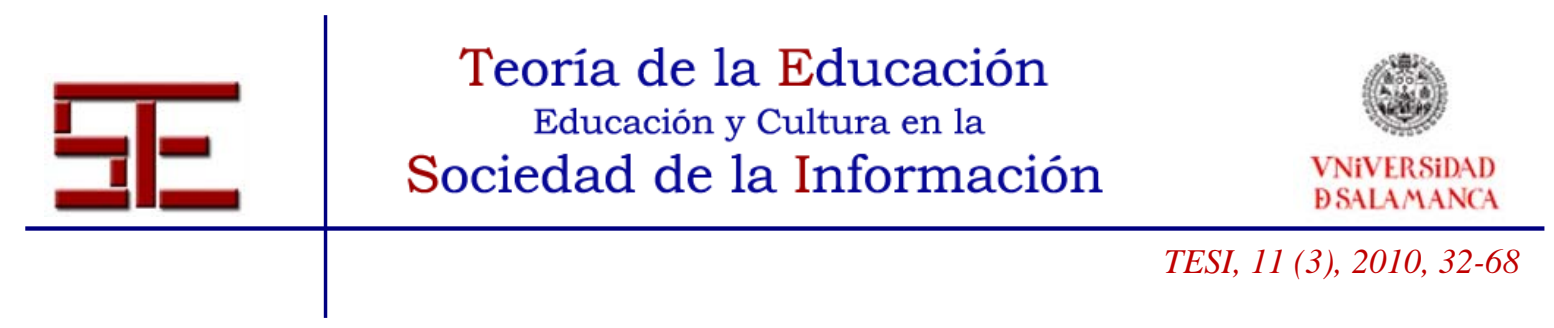

las tecnologías, sino también (a) los modelos y procesos pedagógicos a los que tienen que servir, y (b) los contextos en los que participen los alumnos con las TIC.

El problema es si las TIC pueden ofrecer lo que hacen o deben hacer las buenas universidades. Todo dependerá del tipo de pedagogía que las TIC utilicen. El signo de esa elección va a marcar el futuro haciendo de la revolución tecnológica de las TIC una gran oportunidad cultural del siglo XXI que sirva para rediseñar un nuevo modelo educativo o simplemente se limite a seguir las huellas del modelo replicativo tantas veces denostado.

Uno de los cambios principales en las universidades y en el profesorado es que tienen que dejar de ser tanto una fuente de información para pasar a tener un papel como facilitadores de la generación del conocimiento. Parece obvio, pero no es tan sencillo en la práctica. El profesor universitario de hoy no puede limitarse a transmitir el saber existente sino a formar intelectualmente al estudiante para que sea capaz de seguir aprendiendo de modo autónomo al margen de él. Su gran tarea es llegar a estimular y desarrollar determinadas funciones mentales, como la observación, la clasificación, la ordenación, la relación, el análisis, la argumentación, el razonamiento, la crítica, la creatividad, etc.

Si avanzamos en la dirección equivocada la tecnología per se no ayuda a llegar al lugar correcto. Las preguntas también son inútiles si fallamos al preguntar. Muchos defensores de la tecnología desean mejorar la enseñanza actual pero demasiado a menudo se abstienen de preguntar si la educación tradicional ha estado enseñando los contenidos apropiados. También tratan de cambiar los medios de la educación pero no se hacen las preguntas difíciles acerca de sus objetivos y las finalidades de la educación superior.

Un qué nuevo en la formación precisa de un nuevo cómo enseñar. Requiere estrategias innovadoras, nuevas formas de interaccionar y de facilitar el aprendizaje respecto a conocimientos, habilidades, actitudes y hábitos. Estrategias innovadoras y creativas, constructivas, implicativas, polivalentes, orientadas al aprendizaje, facilitadoras y mediadoras del aprendizaje.

Los cambios más profundos que se nos están demandando no son solamente tecnológicos, sino más bien de mentalidad y de actitud; de ahí la dificultad de producir cambios instantáneos en la educación. En el terreno educativo no se trata meramente de un cambio de instrumentos, sino ante todo de un cambio de mentalidad del profesorado y de las organizaciones y un cambio de paradigma pedagógico.

Puede ocurrir que por una prisa frenética por aplicar los nuevos modos de enseñar, los cómos, nos olvidemos de los para qué, de los fines educativos, que se ven igualmente

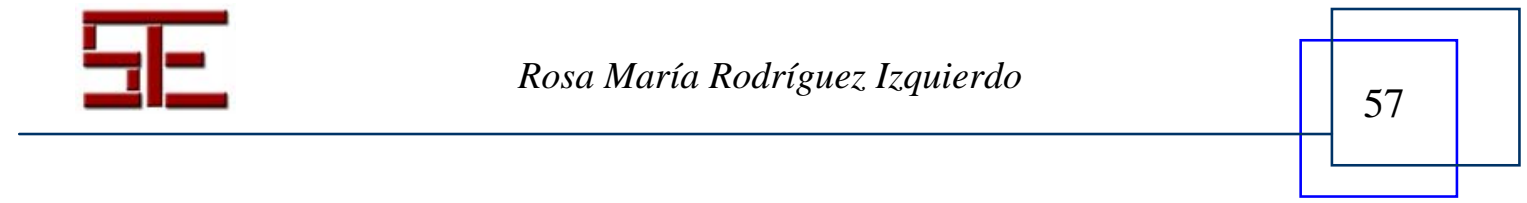




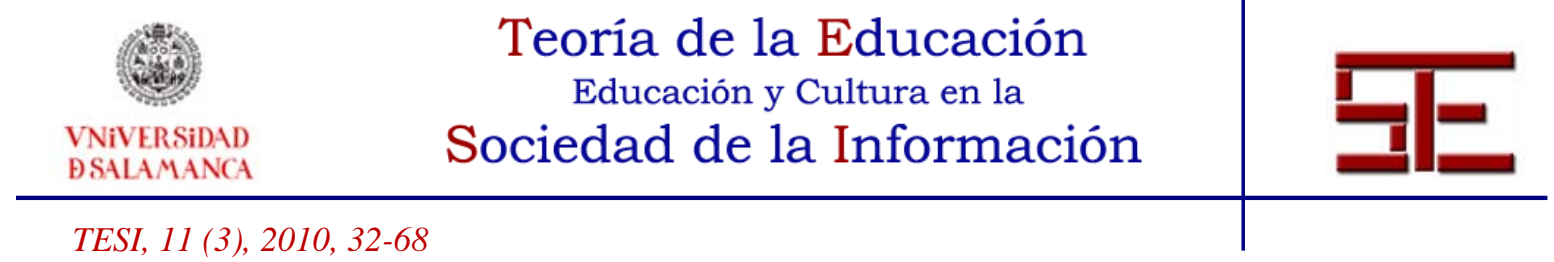

afectados por las tecnologías. Es hora de pensar los para qué de las utilización de estas nuevas tecnologías justo en un momento donde tenemos cada vez más los cómos.

¿Cuáles serían algunas de estas finalidades de la educación superior? Las podríamos resumir como sigue: en este contexto, a nuestro entender, el fin de la educación consistiría en formar a personas capacitadas para recibir información, seleccionarla, criticarla y situarla en modelos conceptuales generales. Más capaces de aprender de una manera continua y de responder con autonomía y responsabilidad personal. La clave, como se ve, está en la promoción y estímulo hacia un tipo de aprendizaje profundamente humano, significativo y no superficial.

En conclusión, en la educación superior hemos caído en la trampa de la subordinación de la pedagogía a la tecnología. Un aspecto a tener en cuenta en el futuro es que el solo uso de las TIC no es suficiente para marcar un cambio en el aprendizaje, sin tomar en consideración los diferentes factores que inciden sobre el individuo en una situación educativa. Desde mi punto de vista, ése es el gran reto que la enseñanza superior deberá asumir en la próxima década. Modificar el significado que tradicionalmente se ha atribuido a la docencia. Lograr un giro del punto de gravedad: que de estar apoyado en la función "enseñanza” pase a hacerlo en la función "aprendizaje”. Desmitificar el secreto que rodea la utilización de estas tecnologías así como diseñar políticas y seguir investigando sobre su utilización pedagógica es una exigencia imperiosa en este momento histórico. Ahora bien, en cualquier caso, hay que utilizar las TIC en combinación con las formas clásicas de la educación y no como un procedimiento de sustitución, autónomo respecto de éstas.

\section{BIBLIOGRÁFIA.}

Alexander, B. (2006). Web 2.0: a new wave of innovation for teaching and learning? Educause Review, 41(2), 32-44.

Anderson, P. \& Blackwood, A. (2004). Mobile and PDA Technologies and their Future Use in Education. Bristol: Joint Information Systems Committee Technology and Standards Watch. Ver http://www.jisc.ac.uk/uploaded_documents/ACF11B0.pdf. consultado el 15 de octubre de 2008.

Area, M. (2005). Internet y la calidad de la educación superior en la perspectiva de la convergencia europea. Revista Española de Pedagogía, 63(230), 85-100.

Armastas, C., Holt, D. y Rice, M. (2006). Balancing the possibilities for mobile technologies in higher education. Ver

http://www.ascilite.org.au/conferences/brisbane05/blogs/proceedings/04_Armatas.pdf. consultado el 17 de octubre de 2008.

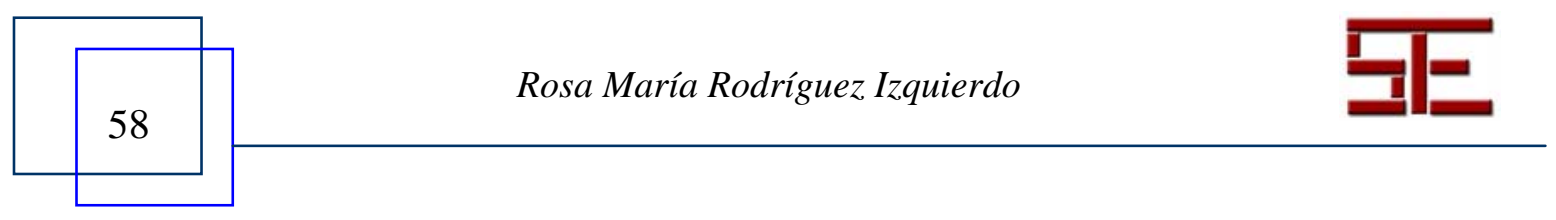




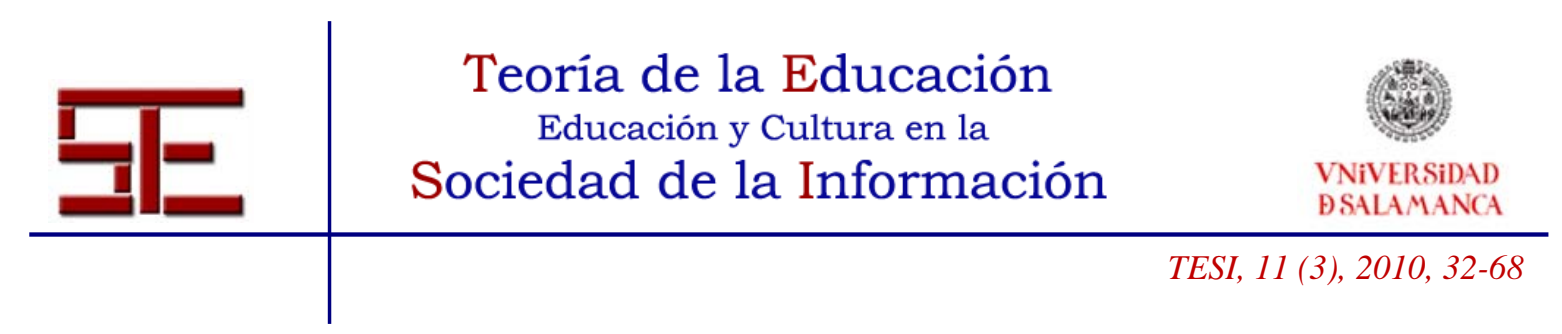

Attewel, J. (2005). Mobile Technologies and Learning: A technology Update and mlearning Project Summary. London: Learning and Skills Development Agency. Ver http://www.lsda.org.uk/files/pdf/041923RS.pdf. consultado el 19 de Nnoviembre de 2007.

Bain, K. (2005). Lo que hacen los mejores profesores de universidad. Valencia: Publicacions de la Universitat de València.

Baldwin-Evans, K. (2006). Key steps to implementing a successful blended learning strategy. Industrial and Commercial Training, 38(3), 156-163.

Barnes, K., Marate, R. C. y Ferris, S.P. (2007). Teaching and learning with the net generation. Innovate, Journal of Online Education, 3(4).

Barone, C. (2001). Conditions for transformation: Infrastructure is not the issue, Educause Review, 36(3), 41-47.

Bates, A. W. (2000). Managing Technological Change: Strategies for College and University Leaders. San Francisco: Jossey-Bass.

- (2004). Why Universities Must Change. Keynote paper to the Open University of Hong Kong, 14 December. Ver http://www.tonybates.ca. consultado el 18 de octubre de 2008.

- (2004). La planificación para el uso de las TIC en la enseñanza. En A. Sangra y M. González Sanmame (Coord.), La transformación de las universidades: a través de las TIC: discursos y prácticas (pp. 31-52). Barcelona: Editorial UOC. Ver http://www.uoc.edu/dt/esp/sangra1104.pdf. consultado el 1 de noviembre de 2008.

Benson, L. \& Harkavy, I. (2002). Saving the soul of the university. En K. Robins y F. Webster (eds.), The Virtual University? (pp. 169-209). Oxford: Oxford University Press.

Breen, R., Lindsay R., Jenkins, A. \& Smith, P. (2001). The role of information and communication technologies in a university learning environment. Studies in Higher Education, 26, 95-114.

Bricall, J. (2000, marzo). Conferencia de Rectores de las Universidades españolas (CRUE) Informe 2000. Barcelona. Ver http://www.oei.es/oeivirt/bricall.htm. consultado el 15 de enero de 2009.

Bueno, C. y Gil, J. J. (coords.) (2007). Las Tecnologías de la Información y la Comunicación en la Educación. Revista Interuniversitaria de Formación del Profesorado, 21(1) monográfico, 17-144.

Butler, D. \& Winni, P. (1995). Feed back and self- regulated learning: A theoretical Synthesis. Review of Educational Research, 65(3), 245-281.

Byrne, M., Flood, B. \& Willis, P. (2002). Approaches to learning of European business students. Journal of Further and Higher Education, 26, 19-28.

Candy, P. (1998). Knowledge navigators and lifelong learners: producing graduates for the information society. En C. RUST (ed.), Improving student learning: improving students as learners. Oxford: Oxford Centre for Staff and Learning Development.

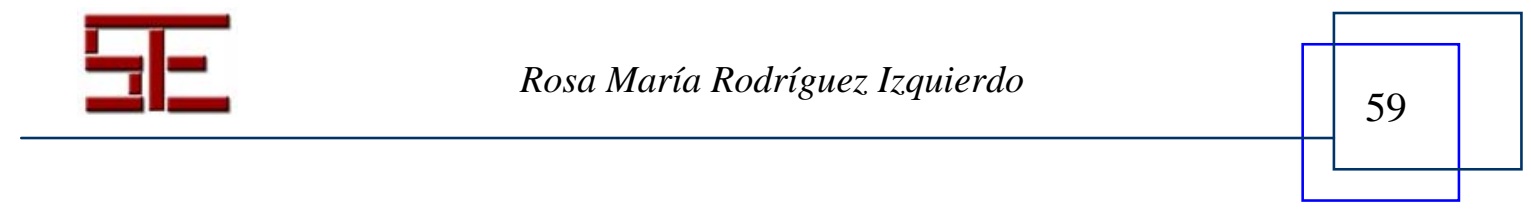




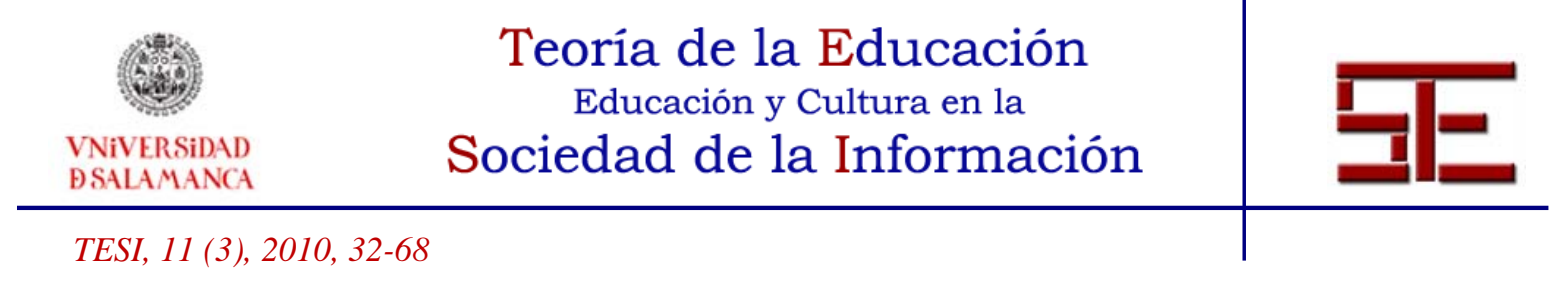

Cebrián, M. (2003). Enseñanza virtual para la innovación universitaria. Madrid: Narcea Ediciones.

Chan, S. \& Lee, M. (2005). An Mp3 a day keeps the worries away: exploring the use of podcasting to address preconceptions and alleviate pre-class anxiety amongst undergraduate information technology students. Charles Sturt Student Experience Conference. Ver http://www.csu.edu.au/division/studserv/sec/papers/chan.pdf. consultado el 18 de mayo de 2007.

Clark, R. E. (1994). Media will never influence learning. Educational Technology Research and Development, 42(2), 21-29.

Corlett, D., Sharples, M., Bull, S. \& Chan, T. (2005). Evaluation of a mobile learning organiser for university students. Journal of Computer Assisted Learning, 21, 162170.

Cradler, J., Mcnabb, M., Freeman, M. \& Burchett, R. (2002). How does technology influence student learning? Learning and Leading with Technology, 29, 46-49.

Cranston, N. (1998). Preparing teacher for the New Millennium: are we doing enough? Journal of In- Service Education, 24(3), 381-391.

Cuban, L. (2008). Frogs into Princes: Writings on School Reform. New York: Columbia University Teachers College Press.

Draper, S. \& Brown, M. (2004). Increasing interactivity in lectures using an electronic voting system. Journal of Computer Assisted Learning, 20, 81-94.

Duart, J. y Lupíanez, F. (2005). E- strategias en la introducción y el uso de las TIC en la universidad. Revista Universidad y Sociedad del Conocimiento, 2(1). Ver http://www.uoc.educ/rusc. consultado el 1 de septiembre de 2009.

Ehrmann, S. C. (1995). Asking the Right Questions: What Does Research Tell Us about Technology and Higher Learning? Change, 27(2), 20-27.

Eriksen, T. H. (2001). Tyranny of the Moment: Fast and Slow Time in the Information Age. London: Pluto Press.

Ertmer, P. A. (1999). Addressing first- and second-order barriers to change: Strategies for technology integration. Educational Technology Research and Development, 47(4), 47-61.

Escudero, J. M. (2006). EEES. ¿Será la hora de la renovación pedagógica de la Universidad? Murcia: ICE.

Finley, L. y Hartman, D. (2004). Institutional change and resistance: Teacher preparatory faculty and technology integration. Journal of Technology and Teacher Education, 12, 319-337.

García-Valcárcel, A. (2003). Tecnología educativa. Implicaciones educativas del desarrollo tecnológico. Madrid: La Muralla.

Geddes, S. (2004). M-learning in the C21st: Benefits for Learners. Ver http://knowledgetree.flexiblelearning.net.au/edition06/html/pra_simon_geddes.htm. consultado el 9 de noviembre de 2006.

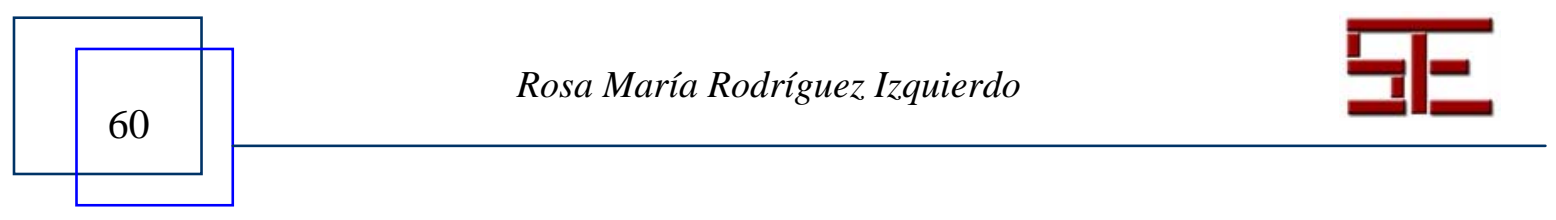




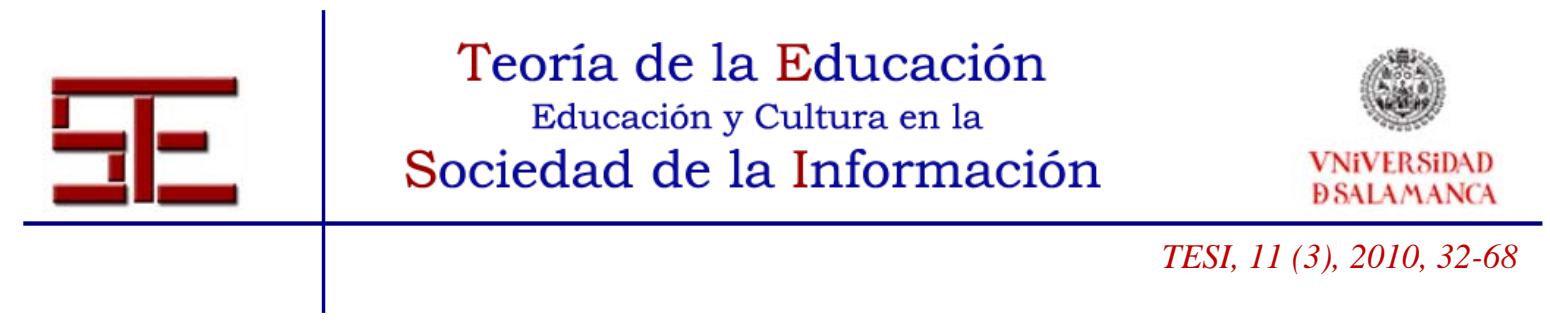

Hall, M. \& Elliott, K. M. (2003). Diffusion of technology into the teaching process: strategies to encourage faculty members to embrace the laptop environment. Journal of Education for Business, 78, 301-307.

Hanna, D. (Ed.). (2002). La enseñanza universitaria en la era digital. ¿Es ésta la universidad que queremos? Madrid: Octaedro-EUB.

Harvey, L. y Knight, P. T. (1996). Transforming higher education. Buckingham: Society for Research into Higher Education and Open University Press.

Hedberg, J. G. (2006). E-learning futures? Speculations for a time yet to come. Studies in Continuing Education, 28(2), 171-183.

Jarvis, P. (2008). The Routledge internacional handbook of Life Long Learning. Florence, KY: Routledge.

Joint Information System Committee (2007). Student expectations study: Key findings from online research and discussion evenings held in June 2007 for the Joint Information Systems Committee. London: Author. Ver http://www.jisc.ac.uk/publications/publications/studentexpectations.aspx. consultado el 25 de marzo de 2008.

Jochems, W., Van Merriënboer, J. \& Koper, R. (Eds.) (2004). Integrated e-learning: Pedagogy, technology, and organization. London: Routledge Falmer.

Jonassen, D., Howland, J., Marra, R.M. \& Crismond, D. (2008). Meaningful Learning with Technology (3. a edición). Upper Saddle River, N.J: Pearson.

Katz, R., Blustain, H., Duderstad, J., Farrintong, G., Goldstain, E., Graves, W. \& Lozier, G. (1999). Dancing with the devil: Information technology and the new competition higher education. San Francisco: Jossey-Bass Publishers.

Keller, C. \& Cernerud, L. (2002). Students' perceptions of E-learning in university education. Journal of Educational Media, 27(1-2), 55-67.

Kellerd, C. (2005). Virtual learning environments. Learning, Media and Technology, 30, 299-311.

Kennedy, G., Dalgarno, B., Gray, K., Judd, T., Waycott, J., Bernett, S. et al. (2007). The net generation are not big users of Web 2.0 technologies: Preliminary findings. Paper presented at the ASCILITE Conference - ICT: Providing Choices for Learners and Learning, Singapore.

Kerr, S. T. (2005). Why we all want it to work: Towards a culturally based model for technology and educational change. British Journal of Educational Technology, 36, 1005-1016.

Kozma, R. B. (1994). Will media influence learning? Reframing the debate. Educational Technology Research and Development, 42(2), 7-20.

Kulik, C. C. y Kulik, J. A. (1991). Effectiveness of Computer-Based Instruction: An Updated Analysis. Computers in Human Behavior, VII(1-2), 75-94.

Laird, T. F. N. \& Kuh, G. D. (2005). Student experiences with information technology and their relationship to other aspects of student engagement Research in Higher Education, 46, 211-233.

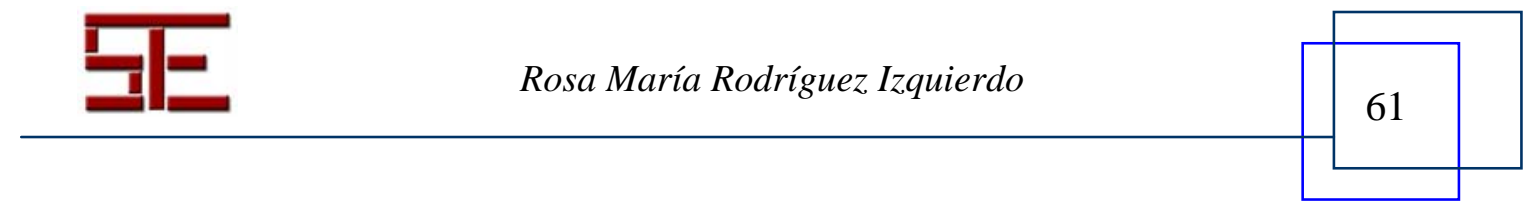




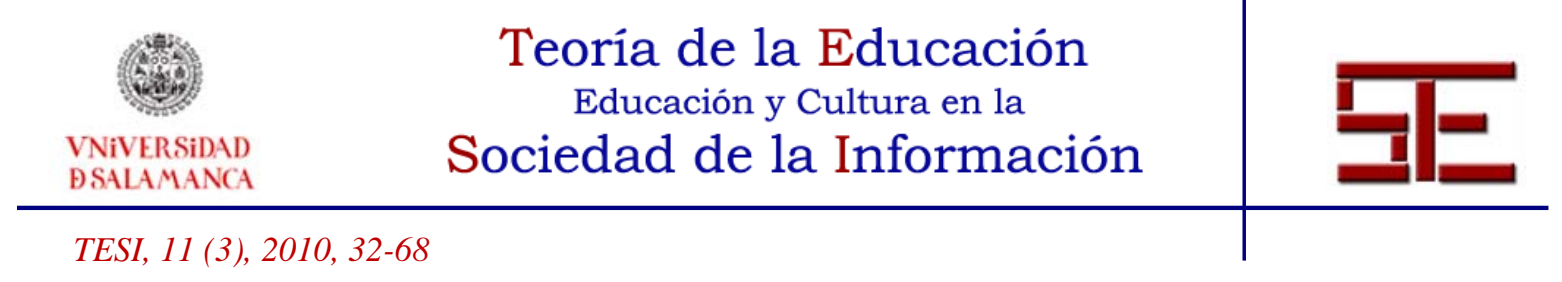

Laurillard, D. (2002). Rethinking university teaching, a conversational framework for the effective use of learning technologies. London: Routledge Falmer.

Lowther, D. L., Ross, S. M. \& Morrison, G. M. (2003). When each one has one: the influences on teaching strategies and student achievement of using laptops in the classroom. Education Technological Research and Development, 51, 23-44.

McManus, T. (1998). Delivering Instruction on the World Wide Web. Ver http://www.utexas.edu/its/unixweb/project.php. consultado el 25 de noviembre de 2004.

McVay, G., Kimberlee, J., Snyder, D. \& Graetz, K. A. (2005). Evolution of a laptop university: a case study. British Journal of Educational Technology, 36(3), 513-524.

Marriott, N., Marriott, P. \& Selwyn, N. (2004). Accounting undergraduates' changing use of ICT and their views on using the internet in higher education. Accounting Education, 13, 117-130.

Martínez, J. (2004). El papel del tutor en el aprendizaje virtual. Barcelona: Editorial UOC. Ver http://www.uoc.edu/dt/20383/index.html. consultado el 17 de enero de 2009.

Martínez Martín, M. (2008). Reflexiones sobre aprendizaje y docencia en el actual contexto universitario. La promoción de equipos docentes. Revista de Educación, número extraordinario, 213-234.

Massachusetts Institute of Technology (MIT) (2006). MITOPENCOURSEWARE. Ver http://ocw.mit.edu/index.html. consultado el 7 de noviembre de 2006.

Michavila, F. (Coord.) (2006). Propuestas para la renovación de las metodologías educativas en la universidad. Madrid: Consejo de Coordinación Universitaria - Cátedra.

Milliron, M. D. \& Miles, C. L. (1999). Aha! The Internet changes nothing. Spring 1999 Advertising Supplement on Technology in Education. Community College Week, 11(18), 3, 8,15.

Mishra, P. y Koehler, M. (2006). Technological pedagogical content knowledge: a framework for teacher knowledge. Teachers College Record, 108(6), 1017-1054.

Moule, P. (2003). ICT. A social justice approach to exploring user issues? Nurse Education Today, 23, 530-536.

Morris, P., Ehrmann, S. C., Goldsmith, R., Howat, K. \& Kumar, V. (1994). Valuable, Viable Software in Education: Cases and Analysis. New York: Primis Division of McGraw-Hill.

Oliver, M. (2003). Looking backwards, looking forwards: an overview, some conclusions and an agenda. En J. Seale (Ed.), Learning technology in transition, from individual enthusiast to institutional implementation. Lisse-Netherlands: Swets and Zeitlinger.

Oliver, M. \& Dempster, J. (2003). Strategic staff development for embedding e-learning practices in higher education, en R. P. Blackwell Blackmore (eds.), Towards Strategic Staff Development? Buckingham: SHRE/Open University Press.

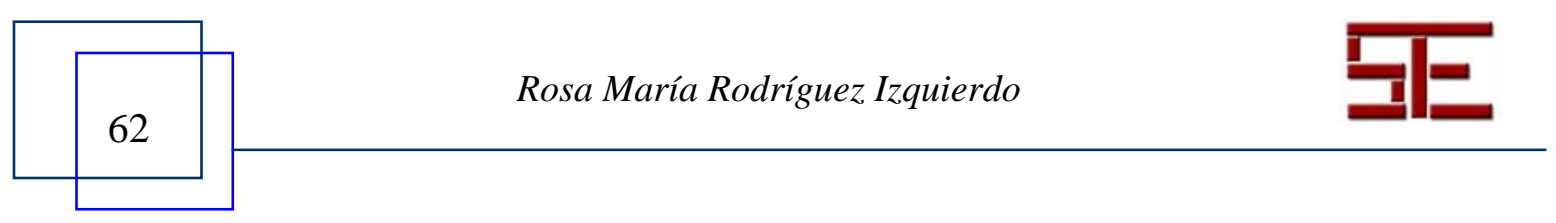




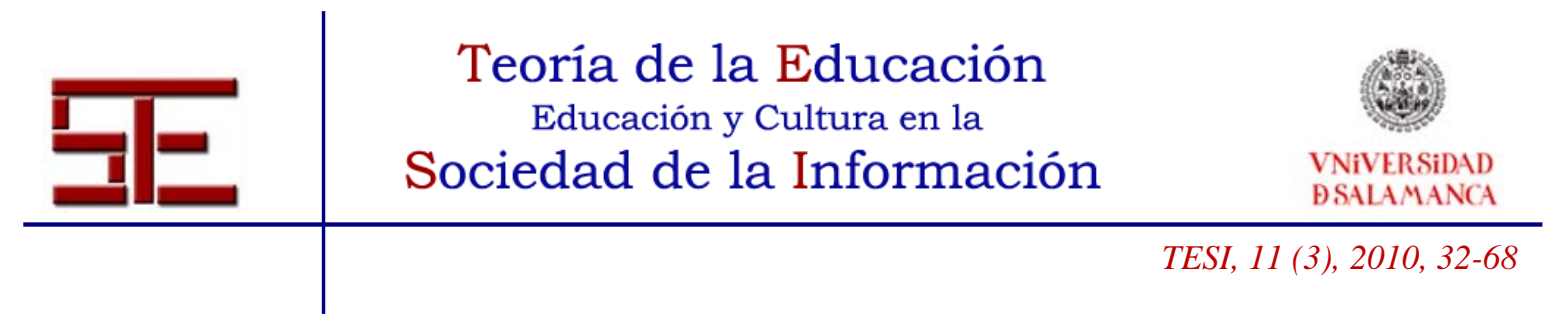

Oliver, R. (2006). Exploring a technology-facilitated solution to cater for advanced students in large undergraduate classes. Journal of Computer Assisted Learning, 22, 112.

Online Computer Library Center and De Rosa, C. (2006). College Students' Perceptions of Libraries and Information Resources: A Report to the OCLC Membership. Dublin, Ohio: OCLC. Ver http://www.oclc.org/reports/2005perceptions.htm, consultado el 17 de enero de 2008.

Organización de Cooperación y Desarrollo Económico (OCDE) (2005). E-learning in Tertiary Education: Where Do We Stand? Paris: Organization for Economic Cooperation and Development.

Owen, P. S. \& Demb, A. (2004). Change dynamics and leadership in technology implementation. Journal of Higher Education, 75, 636-666.

Paredes, J. y Estebanell, M. (2005). Actitudes y necesidades de formación de los profesores ante las TIC y la introducción del crédito europeo: un nuevo desafío para la educación superior, Revista de educación, 337, 125-148.

Pedro, F. (2001). Transforming On-campus Education: promise and peril of information technology in traditional universities. European Journal of Education 36(2), 175187.

Price, L. \& Richardson, J. T. E. (2003). Why is it difficult to improve student learning? en C. Rust (Ed.), 11th Improving Student Learning Symposium, Improving Student Learning: theory, research and scholarship. Oxford: Oxford Centre for Staff and Learning Development.

Reffel, P. \& Whitworth, A. (2002). Information fluency. New Library World, 103, 427435.

Richardson, J. T. E. (2000). Researching student learning: approaches to studying in campus-based and distance education. Buckingham: Open University Press.

Robins, K. \& Webster, F. (2002): The Virtual University? Oxford: Oxford University Press.

Rodríguez Izquierdo, R. M. ${ }^{a}$ (2003). Reaprender a enseñar: Una experiencia de formación para la mejora continua de la docencia universitaria. Revista Interuniversitaria de Formación del Profesorado, 17(2), 79-84.

- (2005). ¿Cambiará Internet los sistemas de enseñanza y aprendizaje? Desafíos y posibilidades. Revista Innovación Educativa; 15, 213-221.

Russel, T. (1997). The no significant difference phenomenon., Raleigh, NC: North Carolina State University. Ver http://www.nosignificantdifference.org/. consultado el 14 de enero de 2009.

Salinas, J. (1998). Redes y desarrollo profesional del docente: entre el dato serendipity y el foro de trabajo colaborativo. Profesorado, 2(1). Universidad de Granada. Ver http://www.uib.es/depart/gte/docente.html. consultado el 31 de septiembre de 2009.

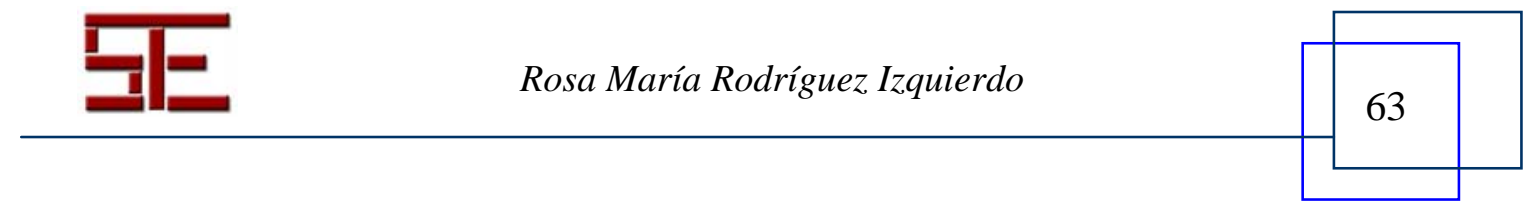




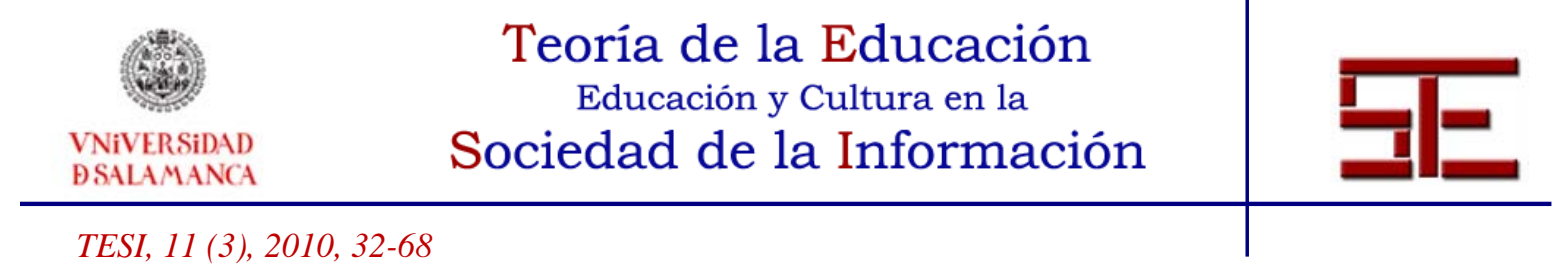

- (2004). Innovación docente y uso de las TIC en la enseñanza universitaria. Revista Universidad y Sociedad del Conocimiento, 1(1). Ver http://www.uoc.edu/rusc/dt/esp/salinas1104.pdf consultado el 7 de enero de 2009.

Sangrá, A. y González Sanmamed, M. (Coord.). La transformación de las universidades: a través de las TIC: discursos y prácticas. Barcelona: Editorial UOC. Ver http://www.uoc.edu/dt/esp/sangra1104.pdf. consultado el 1 de noviembre de 2008.

Schlager, M. \& Fusco, J. (2003). Teacher professional development, technology, and communities of practice: are we putting the cart before the horse? The Information Society, 19, 203-220.

Schmidtlein, F. A. \& Taylor, A. L. (2000). Identifying costs of instructional technology in higher education, Tertiary Education and Management, 6(4), 289-304.

Seale, J. (Ed.) (2003). Enthusiastic implementation: setting the scene for evolution and revolution. En J. Seale (Ed.), Learning technology in transition, from individual enthusiast to institutional implementation. Lisse-Netherlands: Swets and Zeitlinger.

Selwyn, N., Marriott, N. \& Marriott, P. (2000). Net gains or net pains? Business students' use of the Internet. Higher Education Quarterly, 54(2), 166-186.

Selwyn, N. (2003). Why students do (and do not) make use of ICT in university. Paper presented at the Finding Common Ground: IT Education, Dearing and Democracy in the Information Society conference, Leeds University.

- (2007). The use of computer technology in university teaching and learning: a critical perspective. Journal of Computer Assisted Learning, 23, 83-94.

Sevillano, M. L. (2005): Herramientas virtuales y su conocimiento. Enseñanza, 23, 387402.

Sherman, T. \& Kurshan, B. (2005). Constructing learning: using technology to support teaching for understanding. Learning and Leading with Technology, 3(5), 10-39.

Tomás, M., Feixas, M. y Marqués, P. (1999): La universidad ante los retos que plantea la sociedad de la información. El papel de las TIC, Edutec'99. Nuevas tecnologías en la formación flexible y a distancia, 14-17. Universidad de Sevilla. Ver http://tecnologiaedu.us.es/edutec/paginas/117.html. consultado el 4 de enero de 2010.

Twigg, C. A. (1999). Improving learning \& reducing costs: Redesigning largeenrollment courses. National Centre for Academic Transformation. Ver http://thencat.org/Monographs/mono1.pdf. consultado el 7 de enero de 2006.

UNESCO/BIE (1996). Communities and the Information Society: the Role of Information and Communication Technologies in Education. Genova.

University of Leicester (2005). Why use learning technology? Ver http://www.le.ac.uk/talent/elearning/why.html. consultado el 8 de noviembre de 2006.

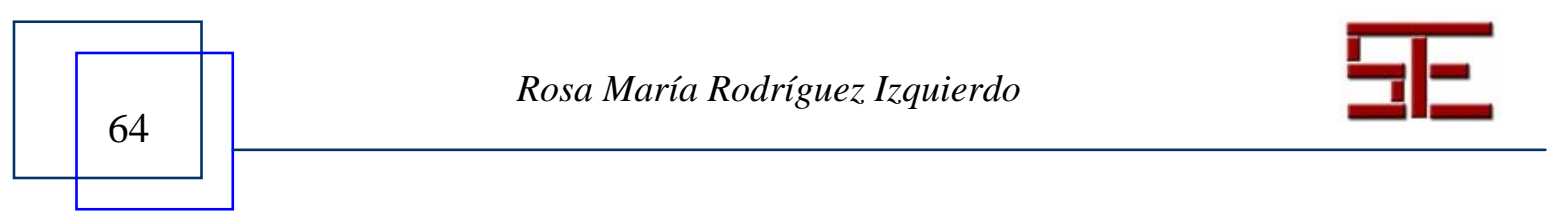




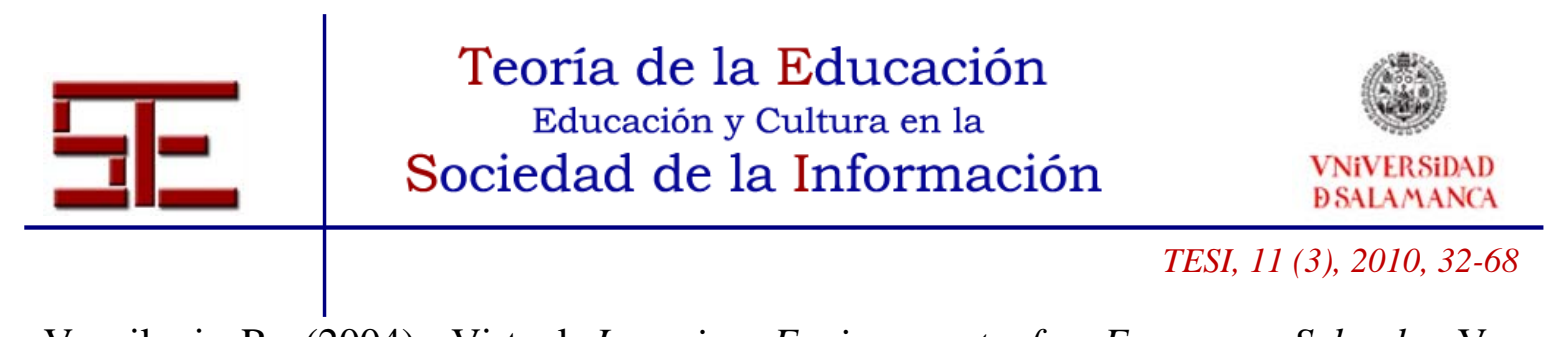

Vuorikari, R. (2004). Virtual Learning Environments for European Schools. Ver http://insight.eun.org/ww/en/pub/insight/misc/specialreports/vle.htm. consultado el 23 de octubre de 2008.

Westbrook, V. (2006). The virtual learning future Teaching in Higher Education, 11(4), 471-482.

Wiske, M. S., Rennebohm Franz, K. \& Breit, L. (2005). Teaching for Understanding with Technology. San Francisco: Jossey-Bass.

\section{Notas}

1 El interés generado por el proceso de Convergencia de la Enseñanza universitaria ha suscitado reflexiones como la coordinada por el profesor Michavila (2006), así como una elaboración continua de informes de investigación como el Programa de Estudios y Análisis (EA) (http://www.centrorecursos.com/mec/ayudas) que han dado lugar a su vez a una abundante literatura sobre convergencia y formación de docentes universitarios, como muestra el monográfico coordinado por Bueno y Gil (2007).

2. Tradicionalmente, las universidades han tenido una función cultural, encargadas de transmitir la experiencia acumulada a lo largo del tiempo. Al mismo tiempo, se les ha asignado preparar a los estudiantes para funcionar en un entorno en el que se pasarían el resto de su vida adulta. Sin embargo, el cambio es tan acelerado que los educadores se preguntan cómo preparar a sus estudiantes para un mundo que no sólo puede ser desconocido para ellos sino que está garantizado que cambiará de manera casi irreconocible.

3. No vamos a profundizar en este momento en lo que significa este hecho. Véase Rodríguez Izquierdo (2005).

4. La Joint Information Systems Committee es la institución principal para el estudio de la evolución de las TIC en la educación superior en el Reino Unido.

5. Podcasting es un término usado para describir un grupo de tecnologías para la distribución de contenido de audio o vídeo a través de Internet.

Para citar el presente artículo puede utilizar la siguiente referencia:

Rodríguez Izquierdo, Rosa maría: (2010). "El impacto de las TIC en la transformación de la enseñanza universitaria: repensar los modelos de enseñanza y aprendizaje”. En De Pablos Pons, J. (Coord.) Buenas prácticas de enseñanza con TIC [monográfico en línea]. Revista Electrónica Teoría de la Educación: Educación y Cultura en la Sociedad de la Información. Vol. 11, n 1 . Universidad de Salamanca, pp. 32-68. [Fecha de consulta: $\mathrm{dd} / \mathrm{mm} / \mathrm{aaaa}$.

http://revistatesi.usal.es/ revistas_trabajo/index.php/revistatesi/article/view/ http://campus.usal.es/ revistas_trabajo/index.php/revistatesi/article/view/5788/5818 ISSN: 1138-9737

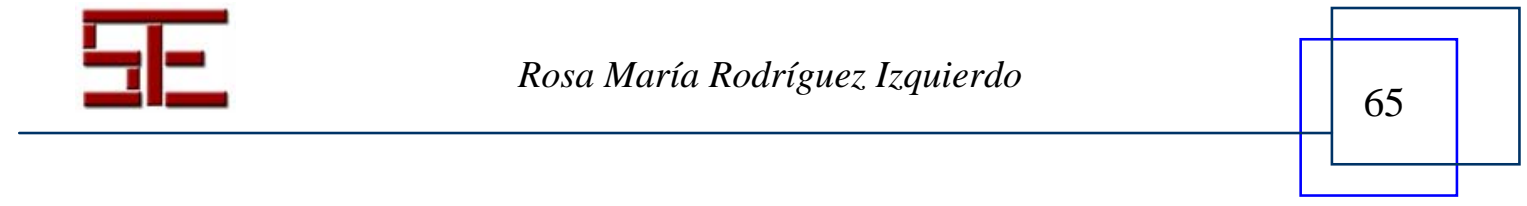

